\title{
الاستكمال الترميمي في الأعمال النحتية الأثرية : ما بين الاساليب التقليدية و الحديثة
}

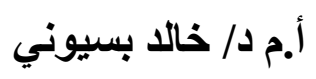

ملغص البحث

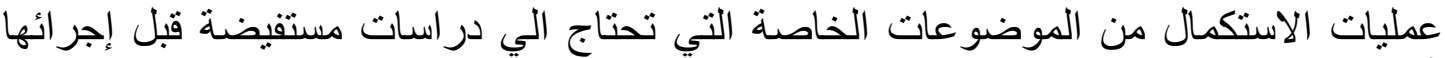

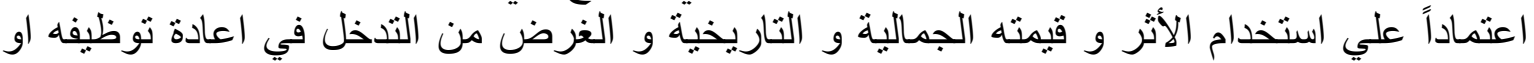

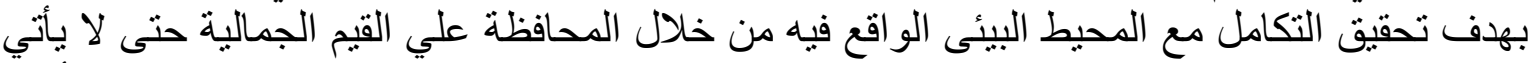

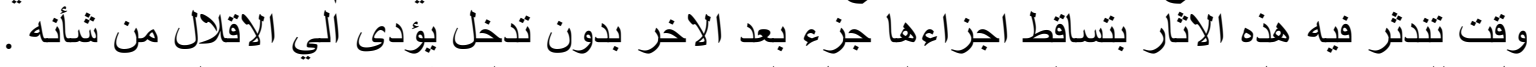

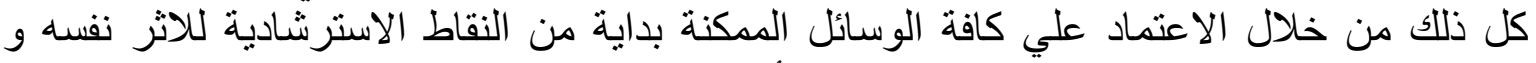

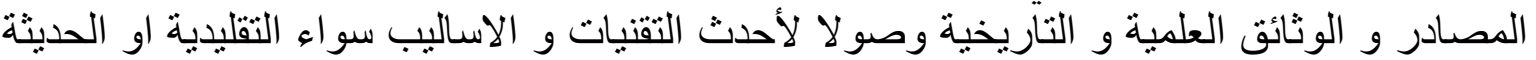

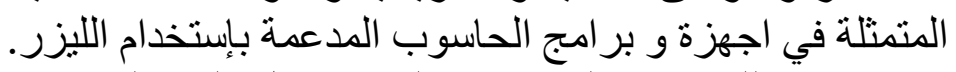

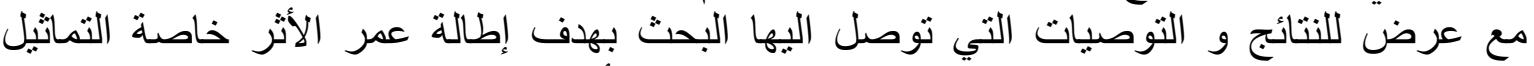

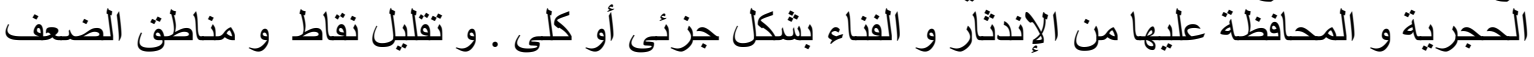
فىى التماثيل خاصة أماكن الإرتكاز مع إضفاء القيمة الجمالية للتمثال لحالته الأصلية و إعادة تأثئيره

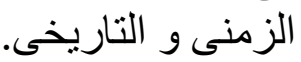

\section{Reconstructive Restoration in Ancient Sculptures : Traditional and New Techniques Summary}

Reconstruction is considered a crucial topic that needs extensive study. Great concern must be given to monuments and ancient pieces of art, particularly, its aesthetic and historical value, in order to be able to rehabilitate it in a way that integrates with its surrounding environment. In doing so, we will prevent the vanishing of such valuable pieces due to the loss of its fragments and parts. This can be achieved by depending on the historical documentation of the monument and utilizing both traditional approaches and new technologies. Contemporary computer applications and the use of laser scanning can be of great help.

Eventually, the research will present its results and recommendations that are aiming to preserve monuments and protect them from vanishing. The research also aims to pinpoint the importance of fulcrum of monuments, especially statues, and the significance of keeping aesthetic and historical values.

الكلمات الدالة : الاستكمال الترميمي - تقنيات الهولوجرام Hologram - جهاز CNC - تلف

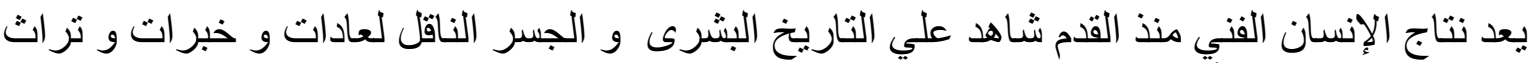

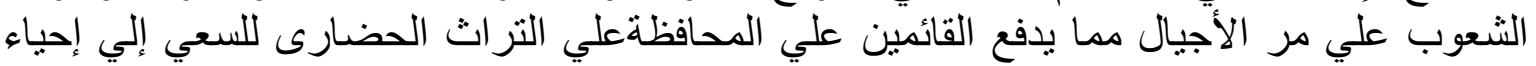

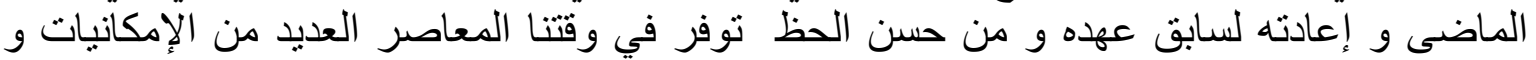

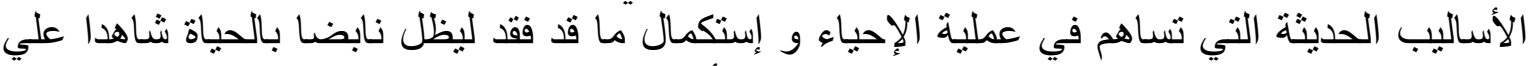

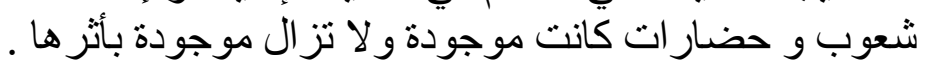

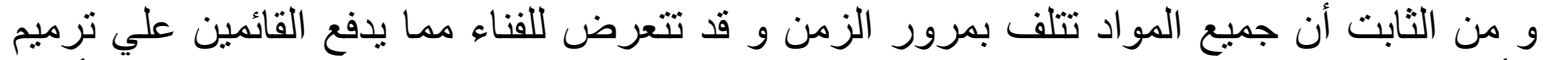
الأثار و الحفاظ علي التراث إلي محاولة الحيلولة دون فنائها و اندثار ها و إطالة عمر ها قدر ما أمكن 
لخلق رابط لا ينقطع في تو اصل الأجيال من خلال إعادة إحياء و ترميم و إستكمال ما فقد من بقايا

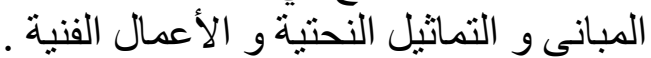

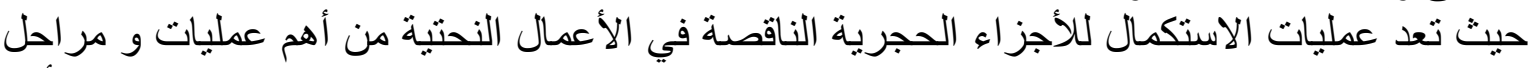

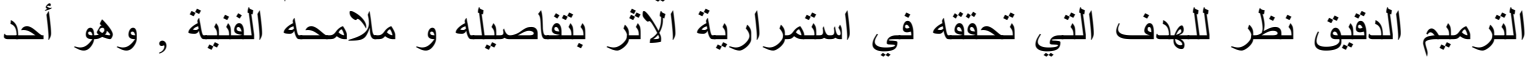

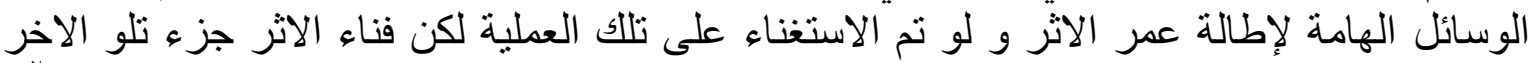

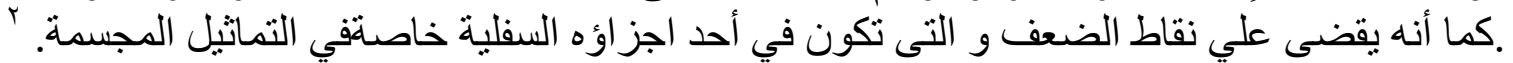

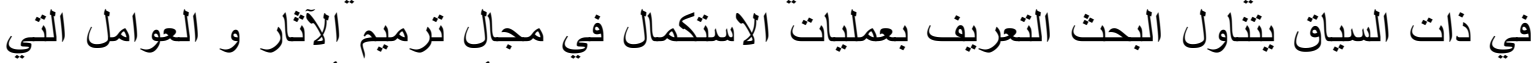

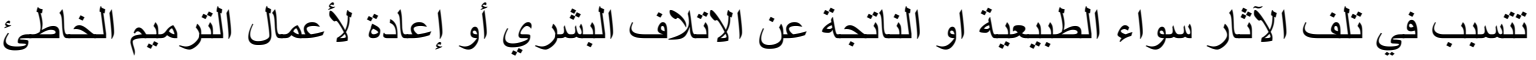

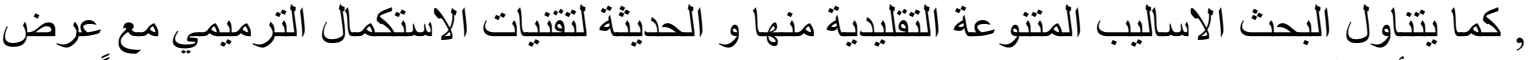

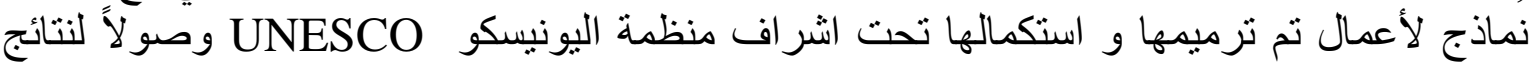

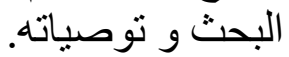

مشكلة البحث

عدم وجود تسجيل كامل و شامل باستخدام التقنيات الحديثة كالهولوجر ام في توثيث الآثار المصرية

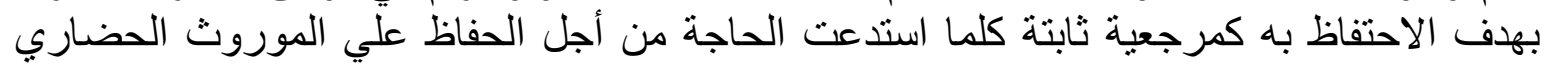
عدم وجود در اسة كافية و وعي من قبل القائمين علي أعمال الترميم بكيفية الاستفادة القصوي من التقنيات الحديثة و لا سيما تقنية الهولوجر ام ام كو توظيف تلك التقنية لأعمال الترميم و الاستكمال. أهمية البحث التعرف علي كافة اساليب الاستكمال الترميمي في مجال الآثار و ما استحدث منها مع التركيز علي

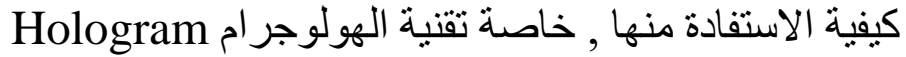
فروض البحث يفترض البحث أن تتيح التقنيات الحديثة بمختلف بر امجها و أدواتها امكانية تسجيل و عرض الأعمال

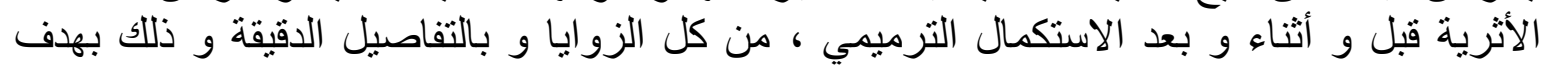
تسجيلهاو الرجو الئه اليها كوثائق تاريخية.

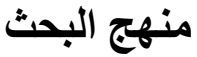

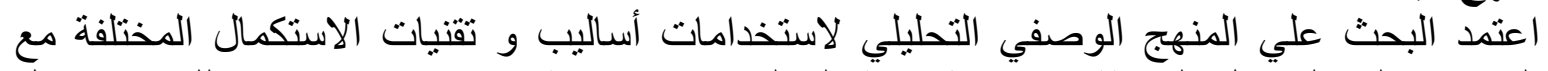

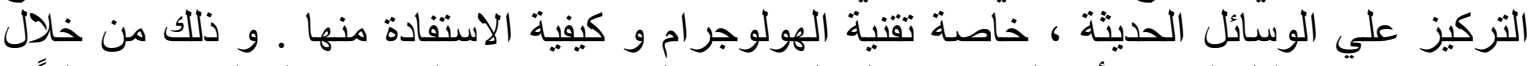
استعر اض و تحليل لبعض أعمال الاستكمال الترميمي التي اعتمدت الته علي تلفي تقنية الهولوجر ام محلياً و عالمياً.

\section{ا ـ أدبيات الدراسة}

\section{1ـ مفهوم الاستكمال الترميمي}

تحتاج عملية الإسنكمال إلي دقة و مهارة و حس فنى عالي يمنلك القدرة علي تحليل و إدر الك تفاصيل

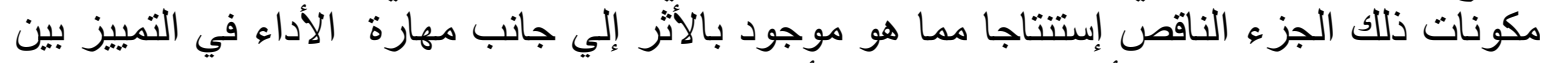

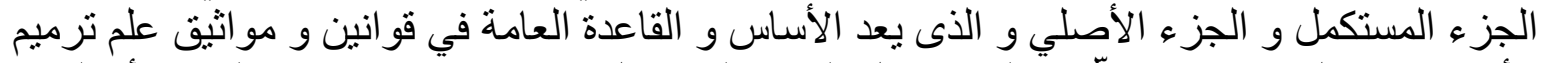

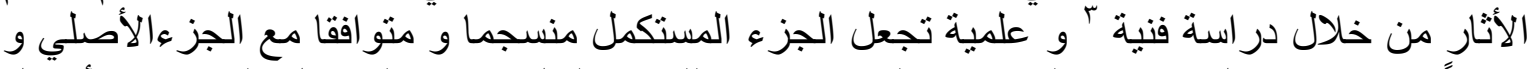

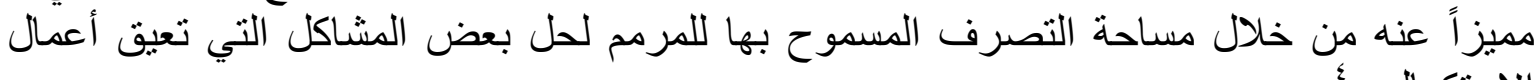

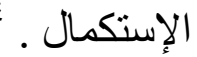




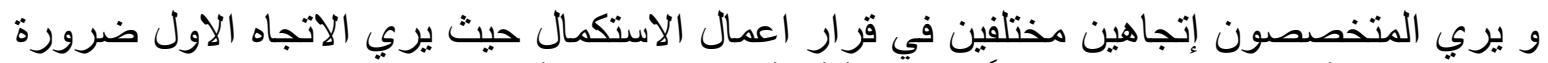

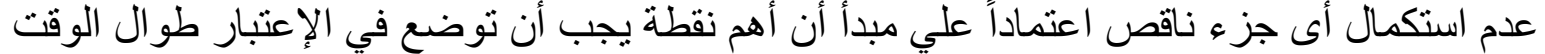

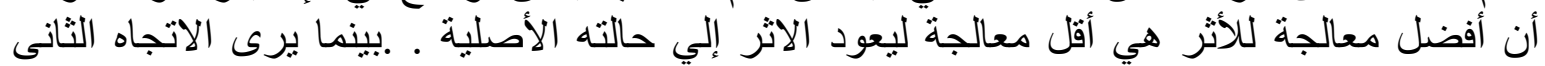
ضرورة حتمية في استكمال الاجزاء الناقصة مع الاخذ في الاعتبار مراعاة مرور الزمن و و ما قد

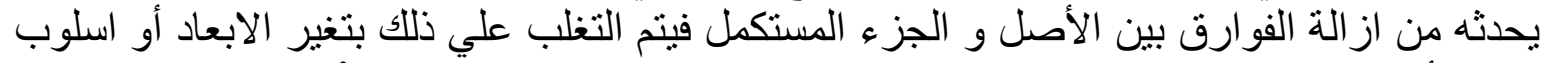

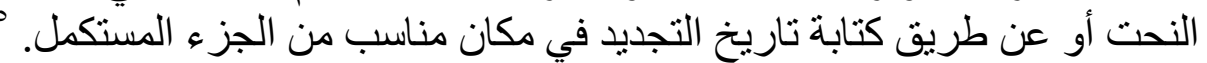

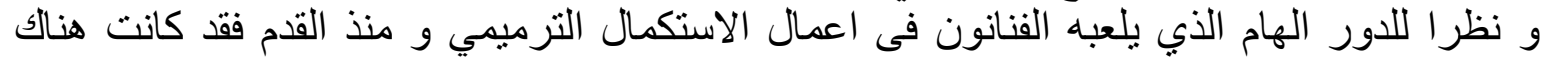

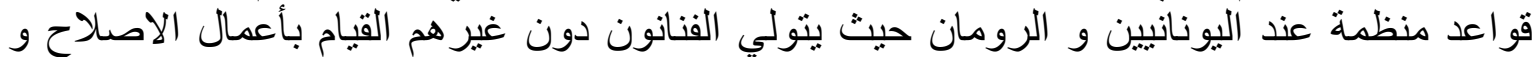

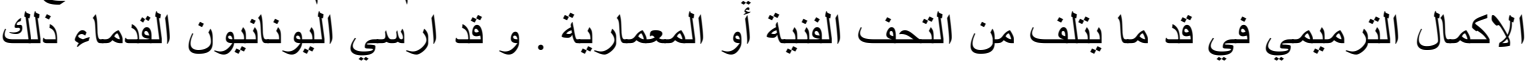

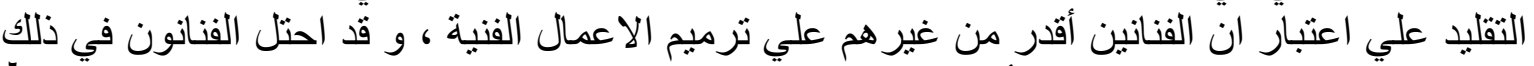

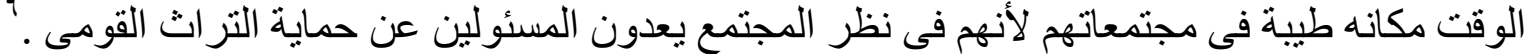

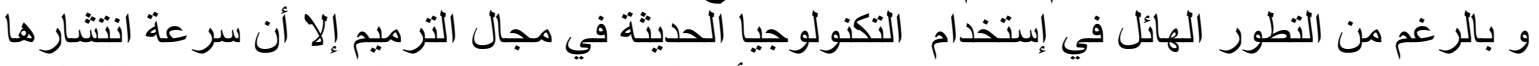
بدون قو اعد ملزمة سوف يؤدى إلي خطورة فقد الأثر للاحساس الفني و التشكيلي الملازم للعمل و

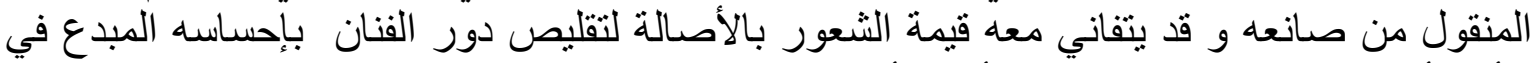

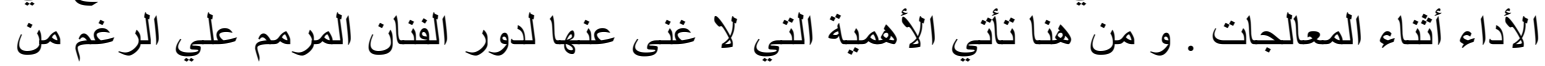

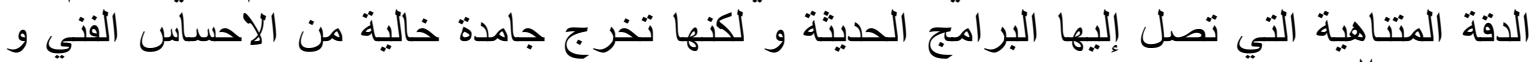

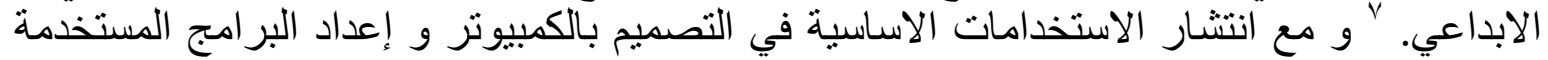

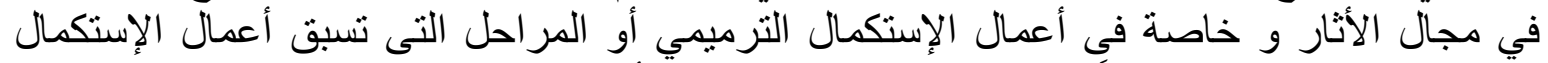

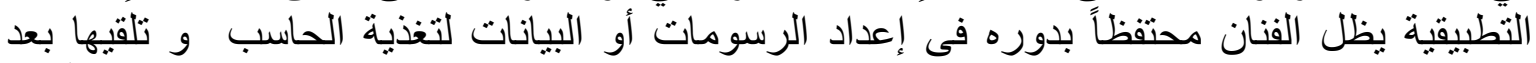
إعدادها من الكمبيوتر و التدخل بالأنسب و الأفضل أثناء الإختيار و التشغيل علي الأثر الأصلي .

\section{الترمي عوامل تلف الأعمال النحتية التي تستلزم معها ضرورة التذخل بالإستكمال}

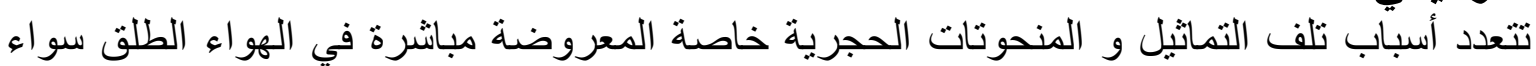

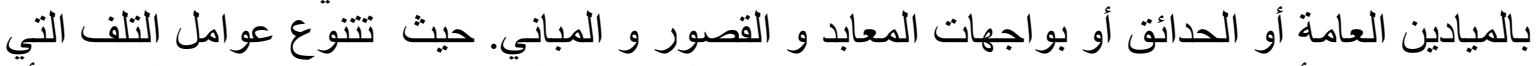

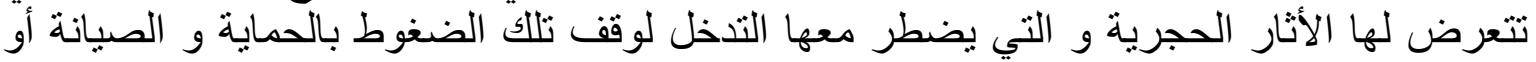

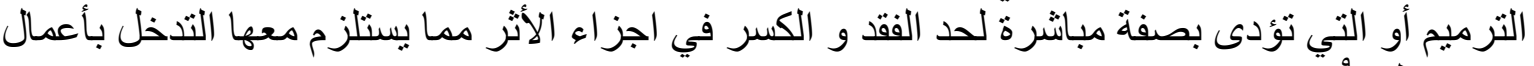

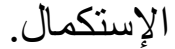

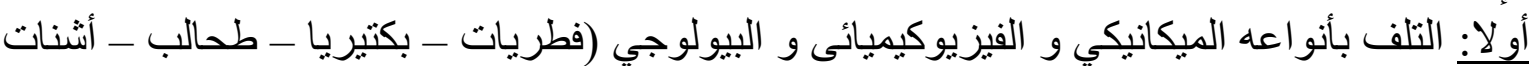

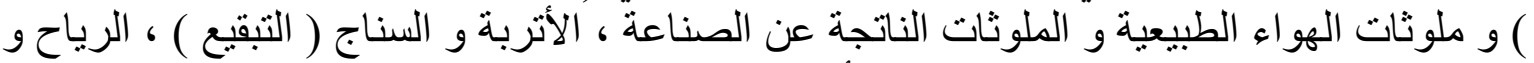

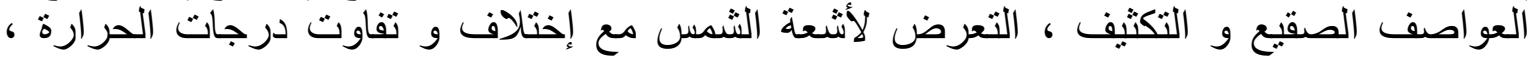

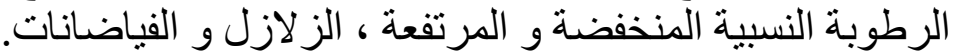

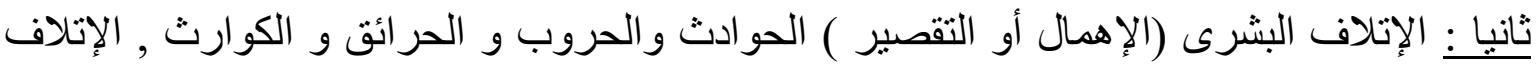

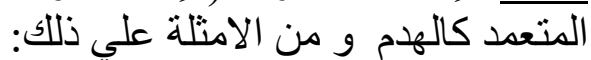

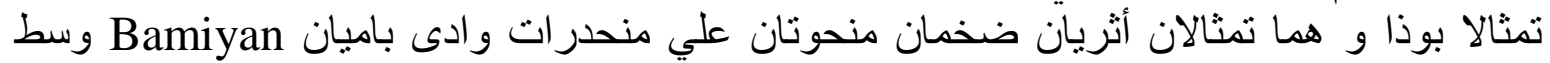

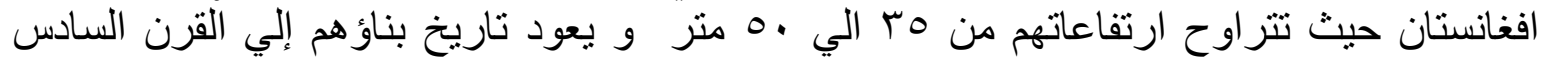

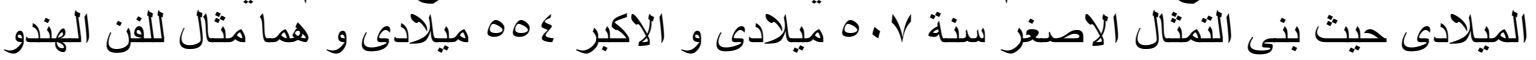

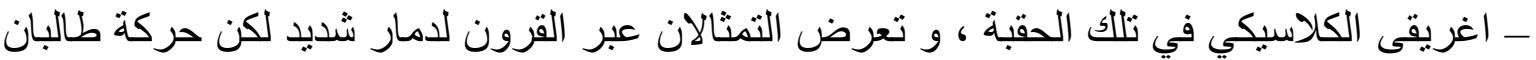

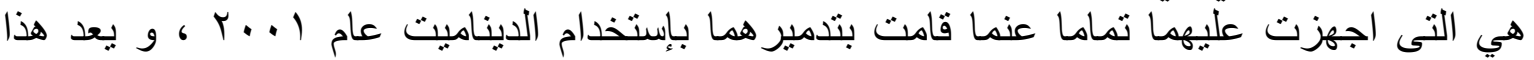


الموقع أحد مو اقع اليونيسكو المسجلة ضمن التراث العالمى منذ ب . . ب. . و قد تم استخدام تقنية

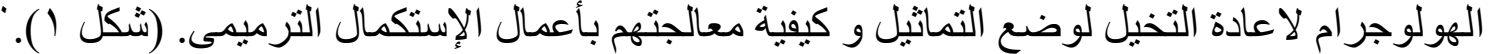

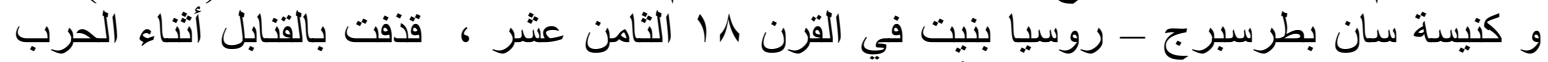

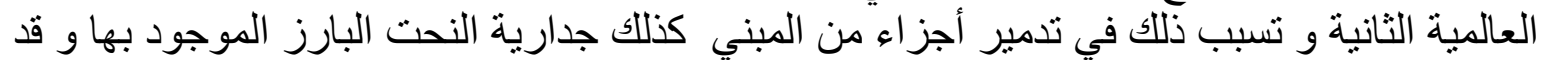
قامت اليونسكو بتولي رعايتها كأحد المشاريع و التي اجريت علئ عليها الأساليب الحديثة في أعمال الترميم

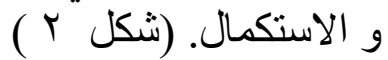
بالاضافة الي كاتدر ائية نوتردام و التي شيدت في القرن الترن التاسع و تعد من أهم معالم التراث العالمى

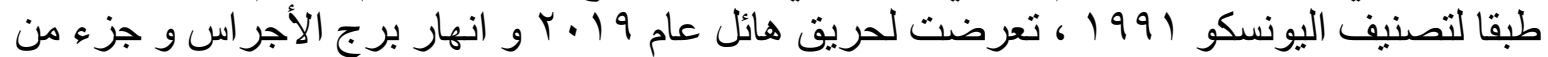
السقف حيث تم استخدام تقنية 3D فى أعمال رصد التلف و التصوير في العلاج و الإستكمال بإثتر الك

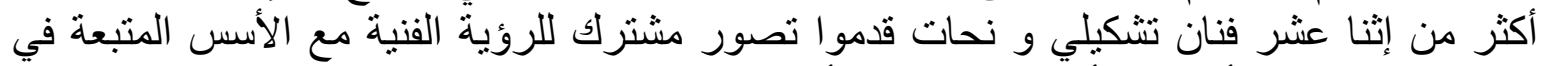

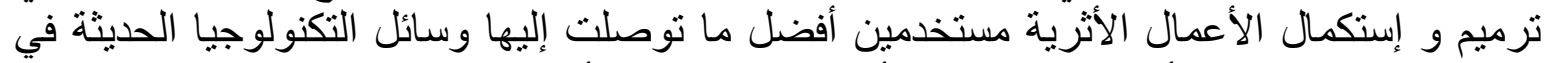

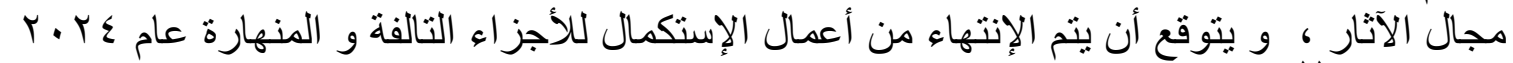

\section{r - ـ أعمال الاستكمال الترميمي اللازمة لعلاج التلاخلات الخاطئة}

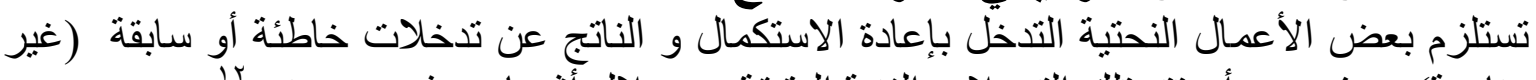

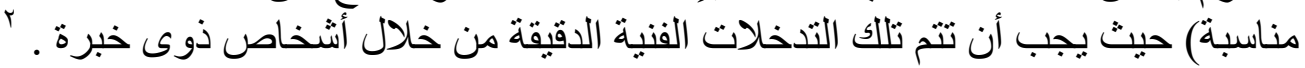

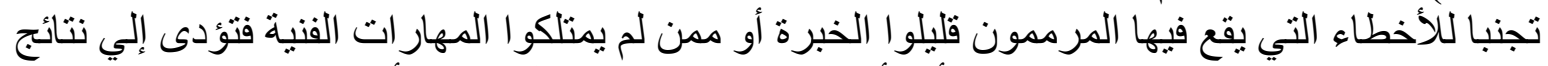

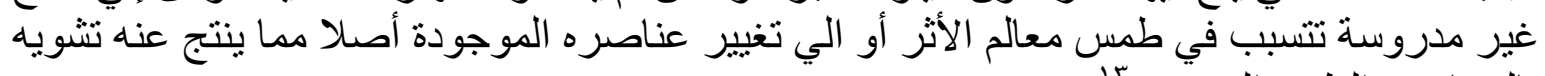

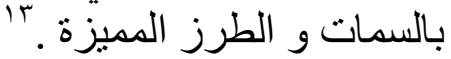

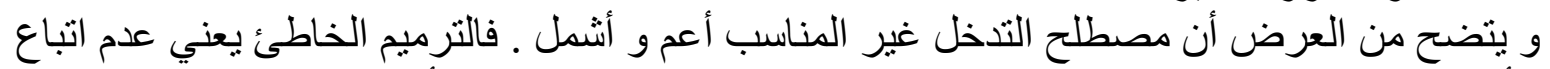

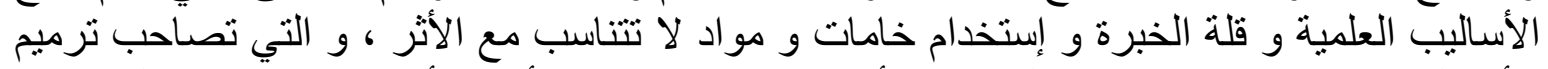

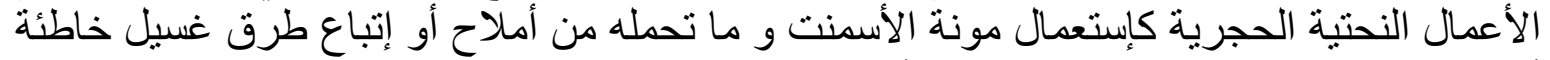

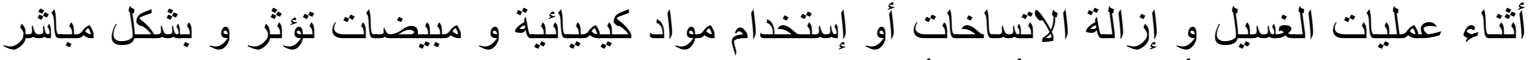

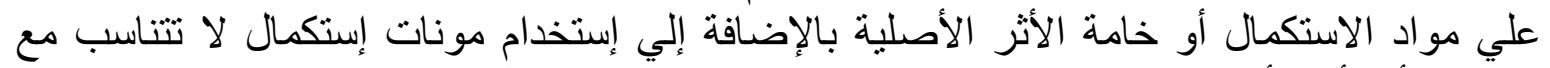

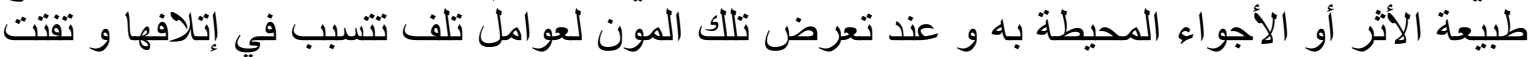

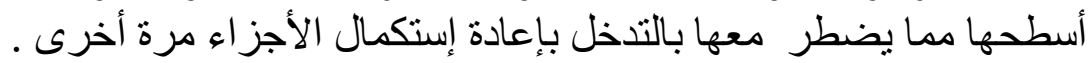

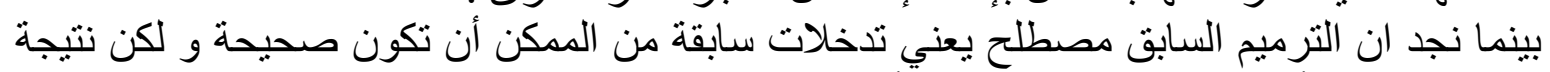

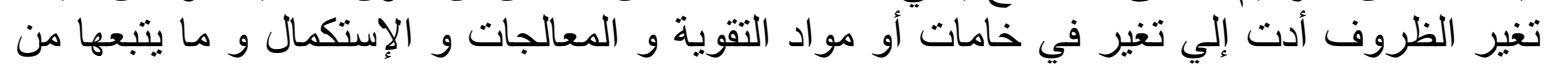

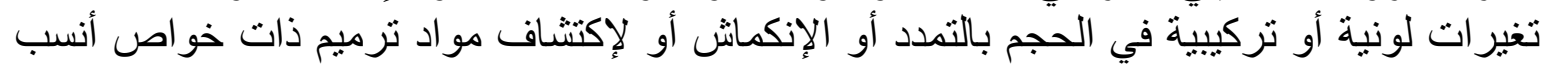

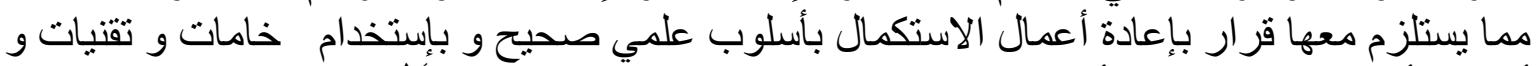

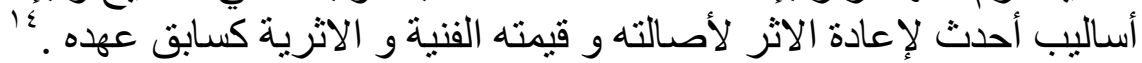

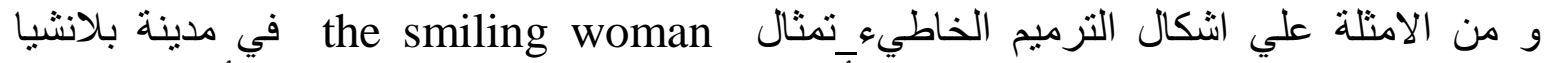
Plancia الفني و التي انتهت ان لقب التمثال هناك ب Potato Head نتيجة عدم الاحترافية في أعمال

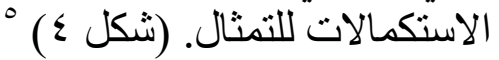

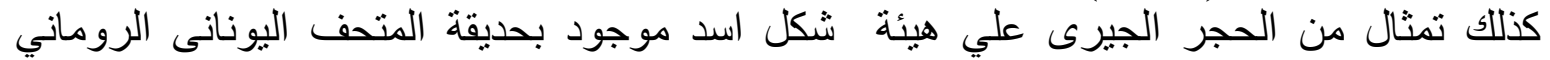
بالإسكندرية و قد اجريت لله إستكمالات سابقة بشكل خاطىى يتض فئح فيها الاستكمال الغير منطقى للبطن

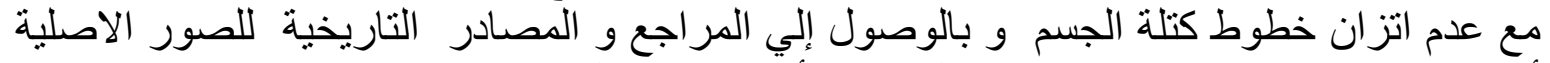

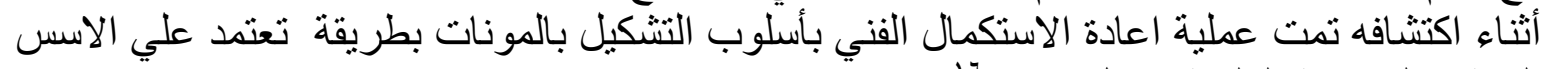


كما رصدت احد الدقالات الاثرية المتخصصة اثني عشر عملا ترميميا عصف بقيمة القطع الاثرية .

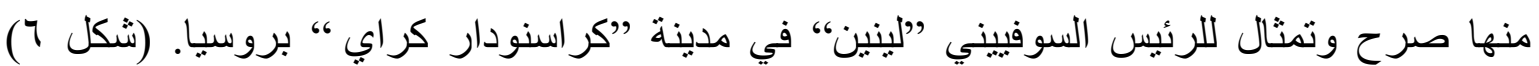

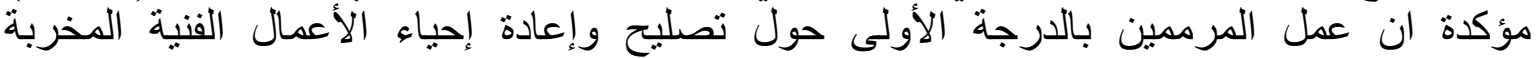

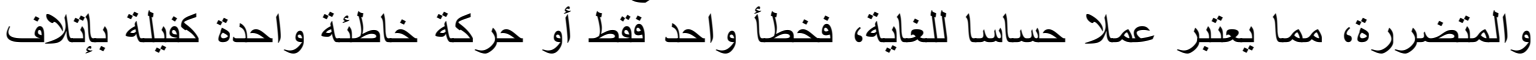

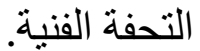

\section{r- أساليب الإستكمال الترميمي في الأعمال النحتية الأثرية}

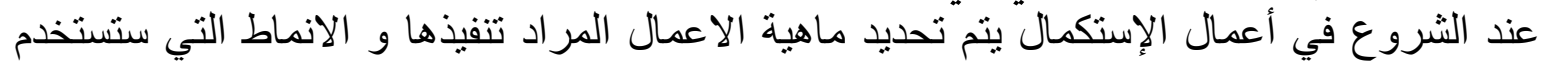

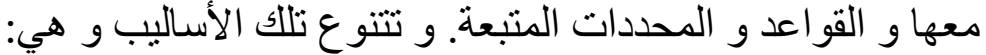

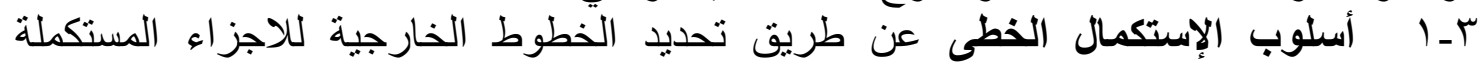

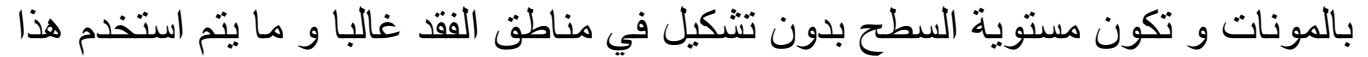

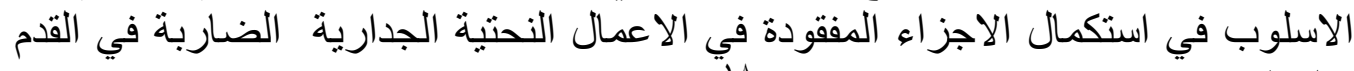

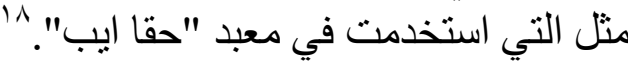

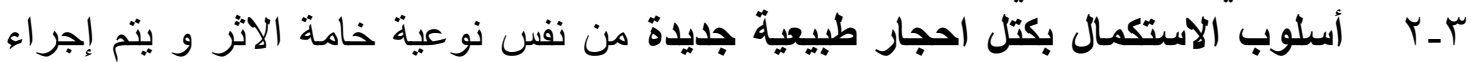

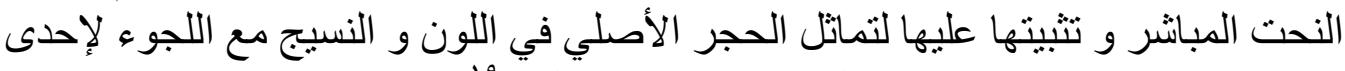

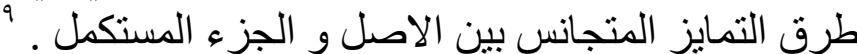

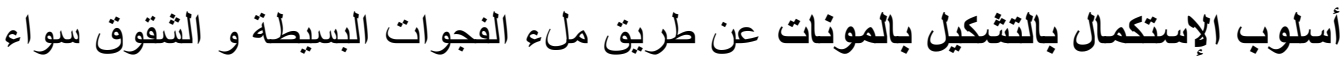
$r_{-}$

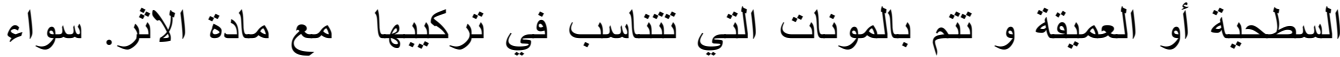

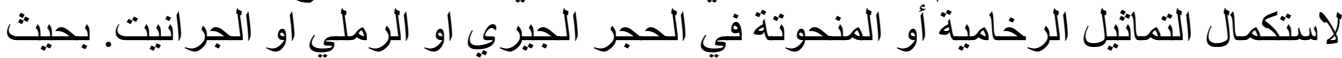

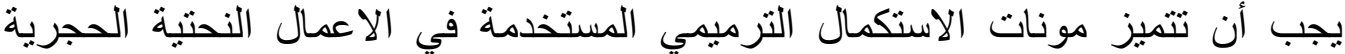

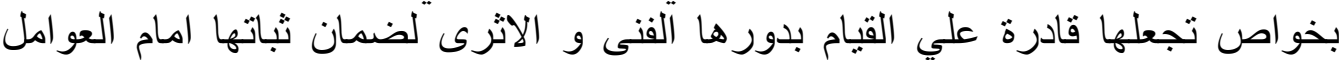

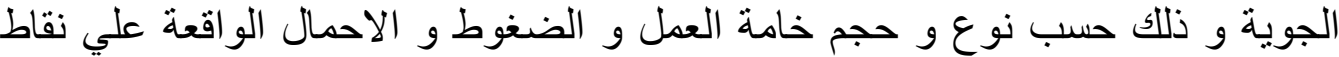

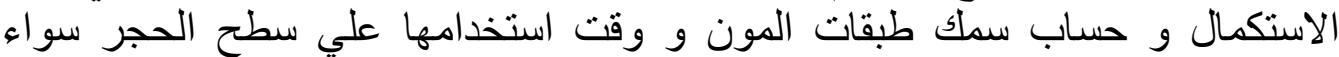

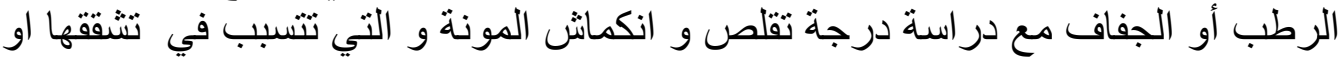

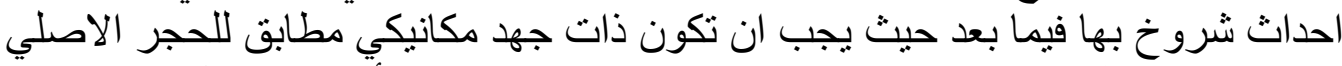

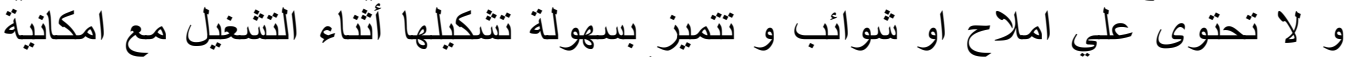

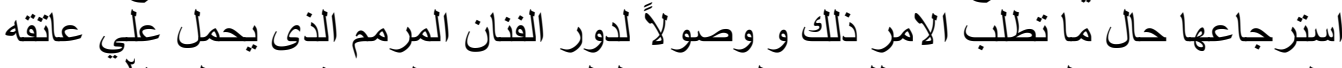

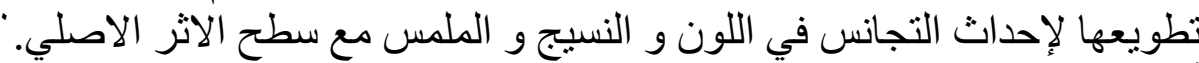

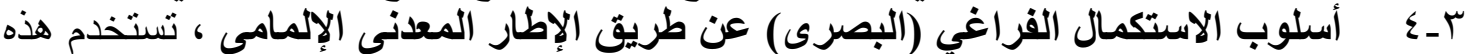

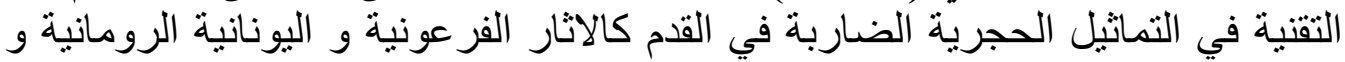

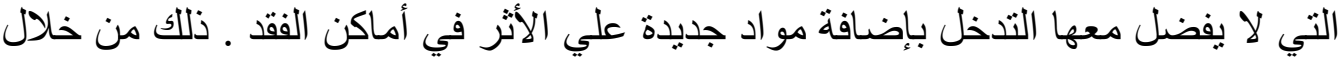

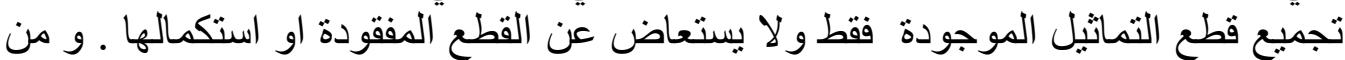
خلال تحديد دقيق مبنى علي دراسة علم التشريح و السمات و والقو القو اعد التشكيلية يتم تنتيتها

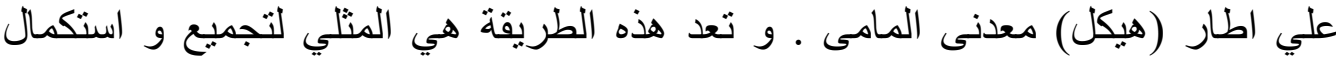

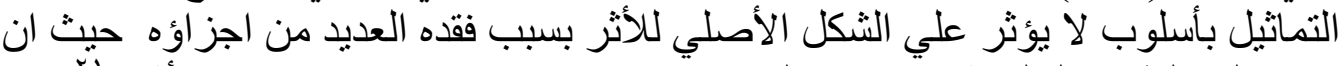

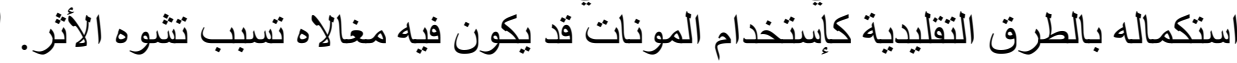

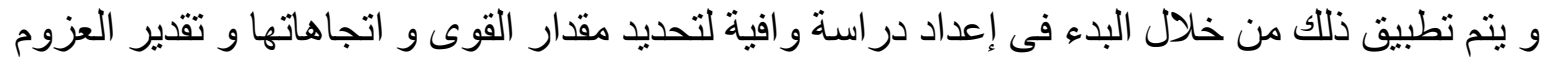
و الاحمال و مر اكز الثقل الو اقعة علي اجز اء كتل التمثال خاصة كبيرة الحجم، مع الاستعانة بقو اعد و لتو 


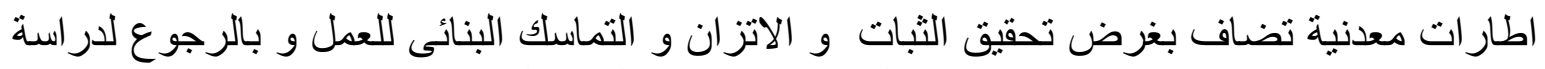

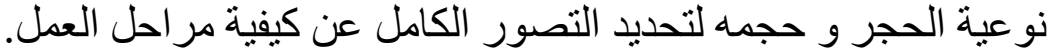

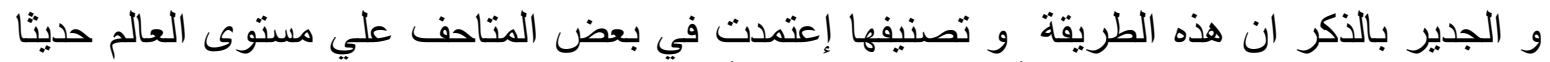

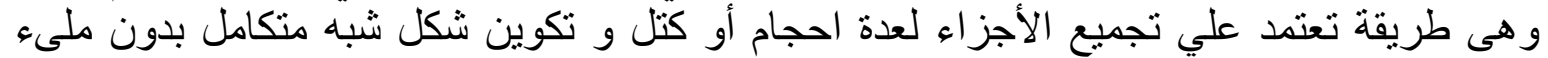

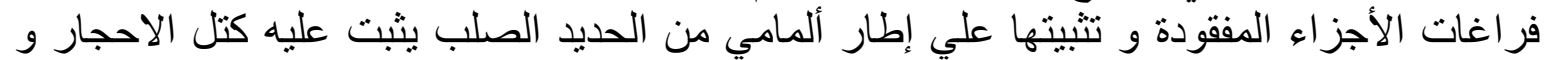

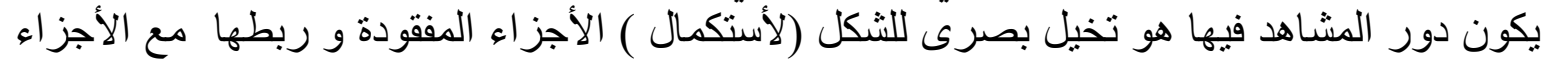

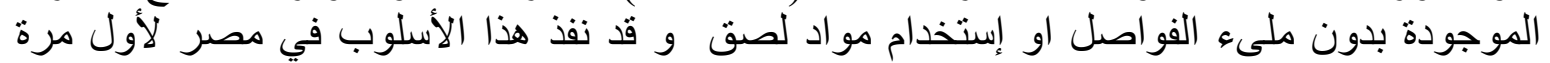

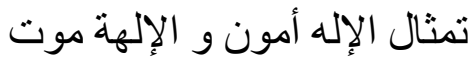

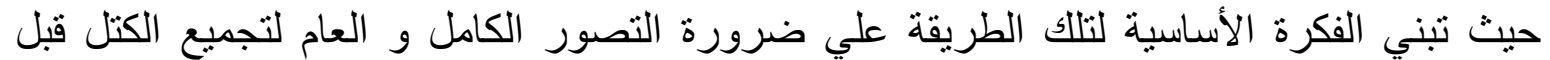

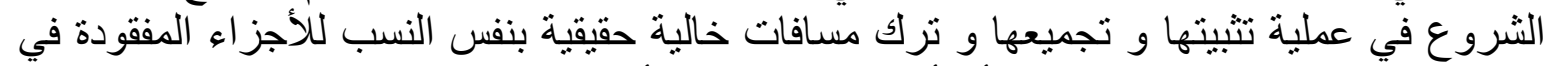

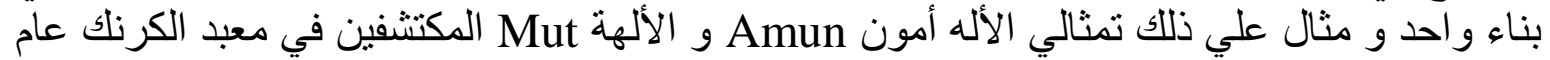

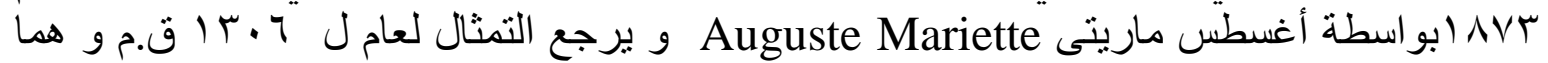
من الحجر الجيرى و موجودين حاليا في المتحف المصرى بالتحرير بعد إجراء لعاء لعلية الإستكمال

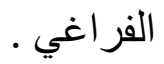
و قد نم إكتشاف أجزاء و قطع أخرى لاحقا اثثاء عمليات التنقيب بمعبد أمون و تم إرسالها إلي مخازن

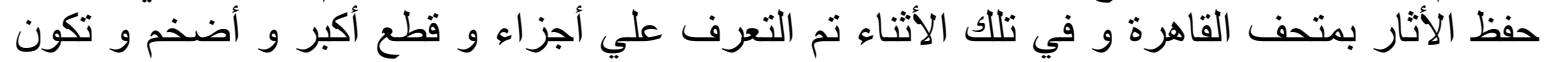

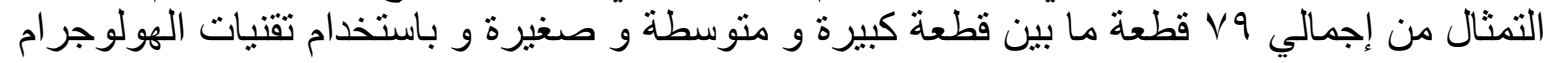

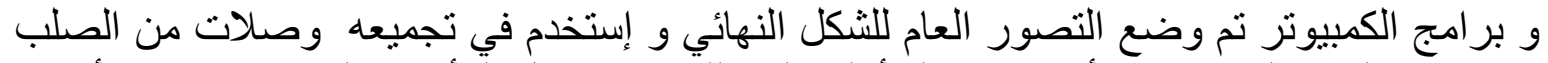

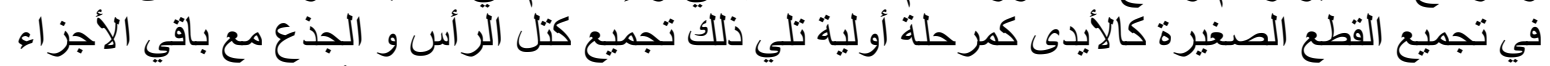

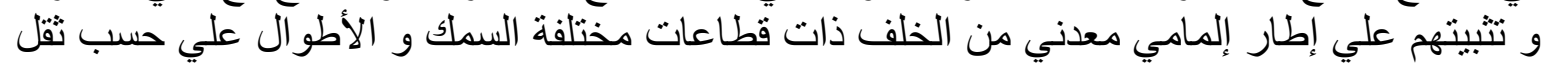

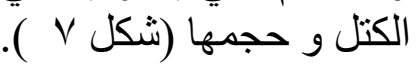

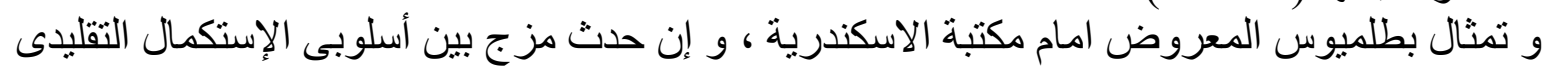

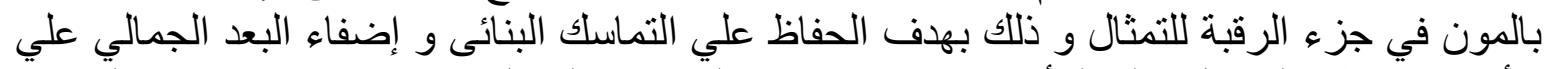

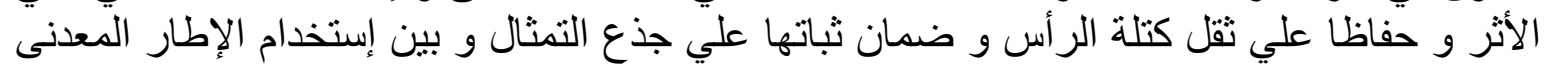

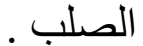

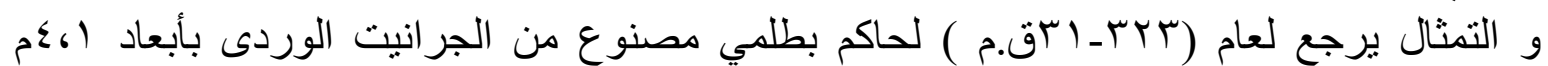

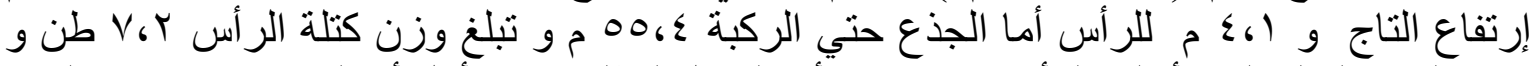

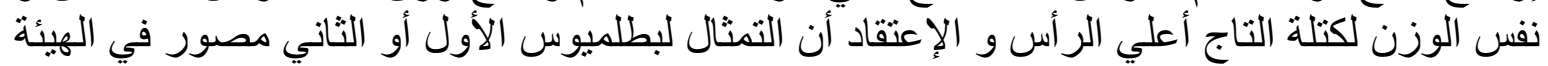

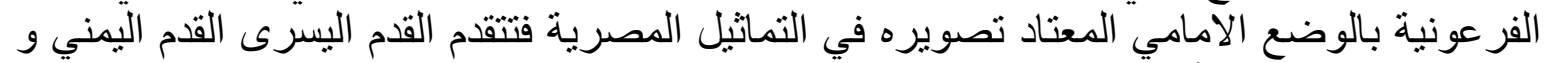

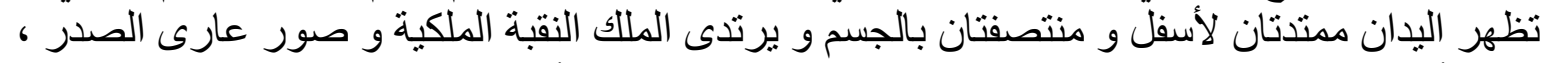

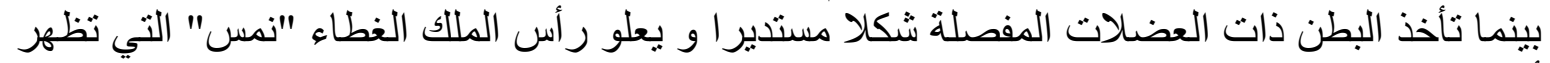

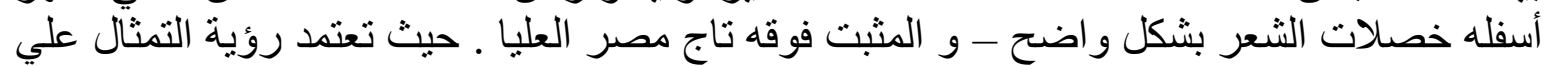

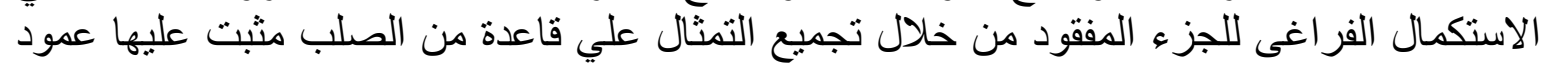

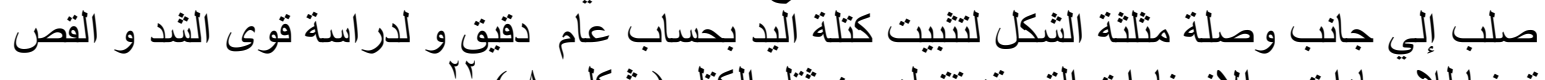

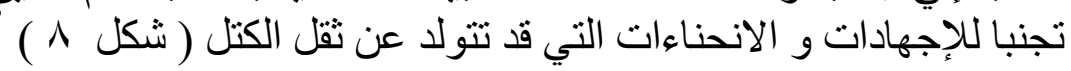

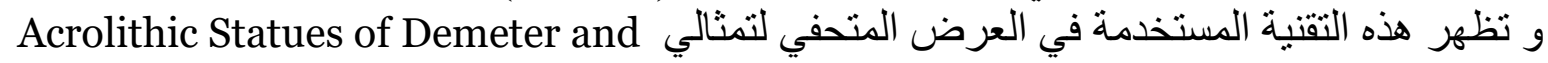
Cبre from Morgantina

و هناك أسلوب أخر استحدث غير التجميع على الإطار بواسطة المسامير و الوصلات المعدنية العادية

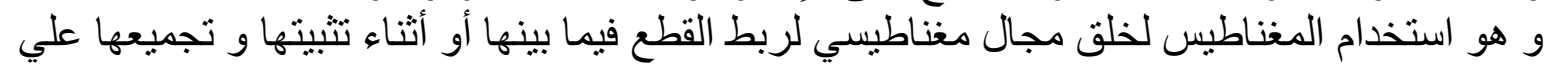




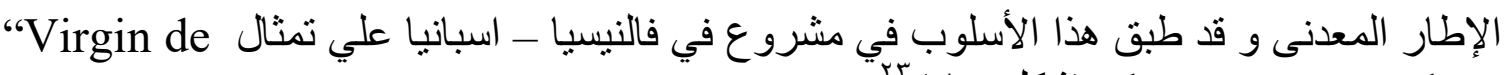

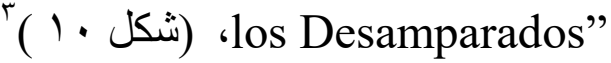

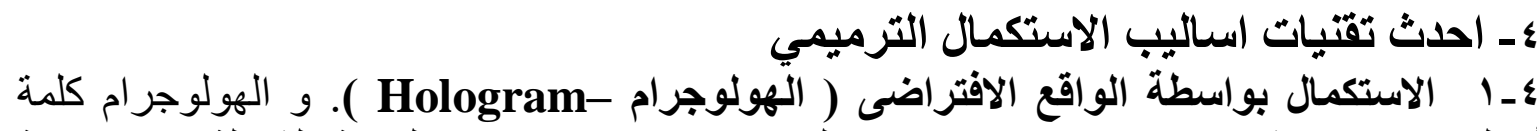

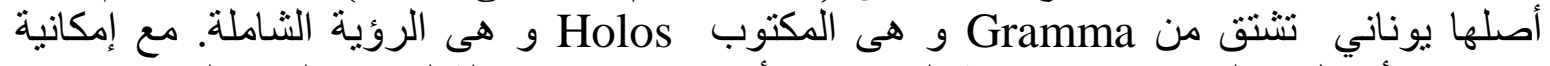

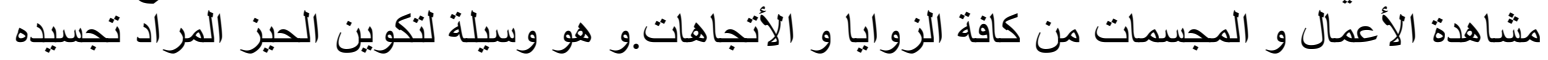

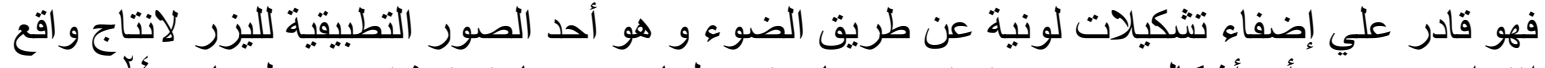

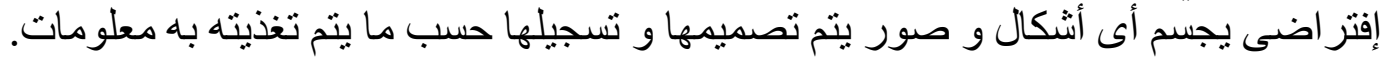
و يمكن تحديد الفرق بين الهولوجرام والهولوجراف ، حيث يطلق مصطلح الهولوجر اف على على عملية

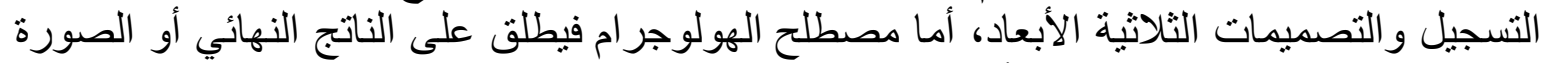

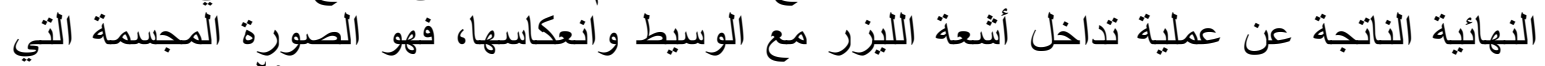

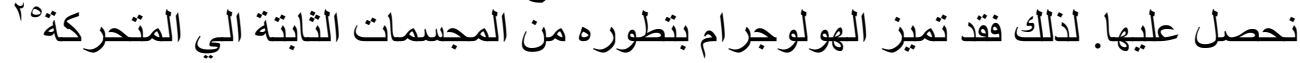

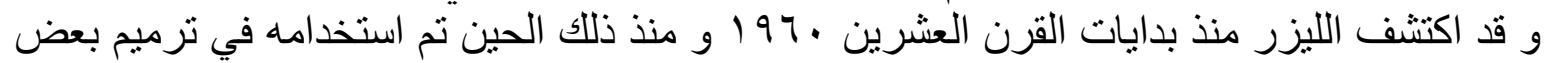

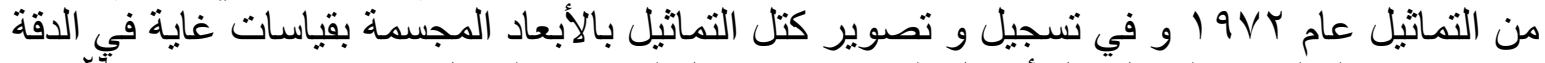

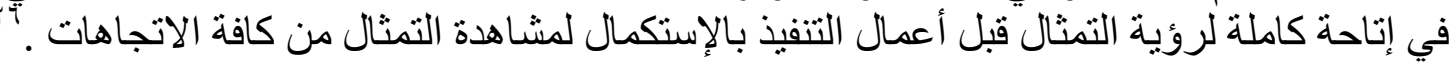

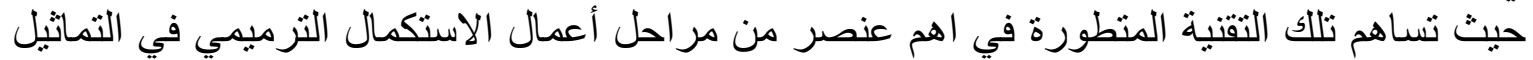

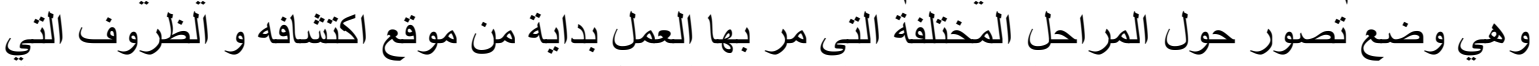

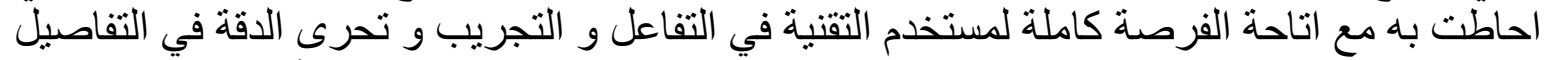

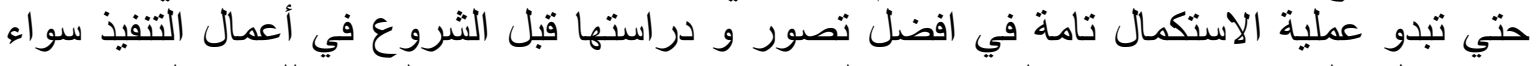

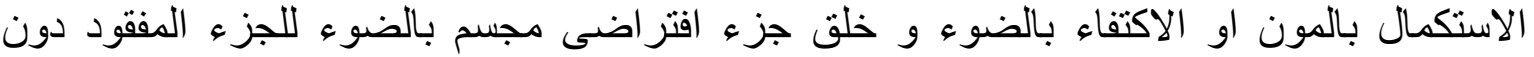

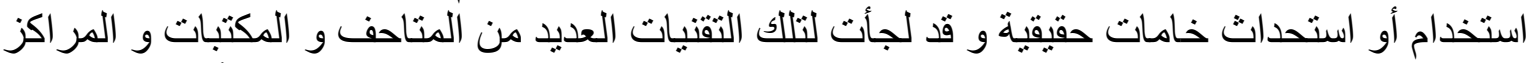

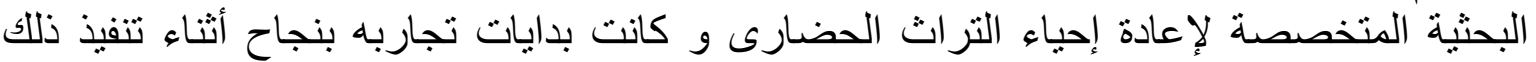

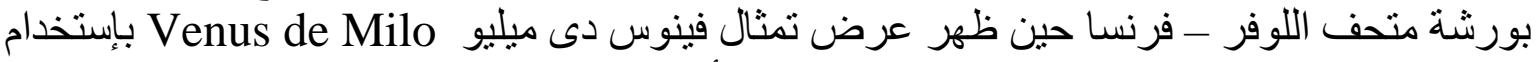

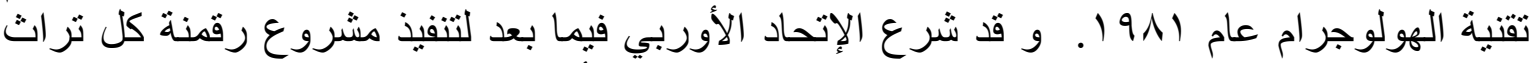

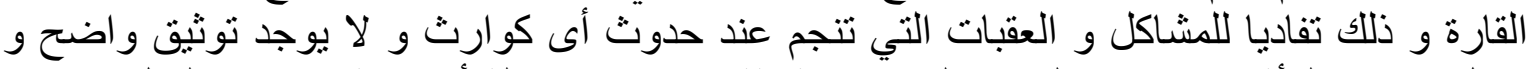

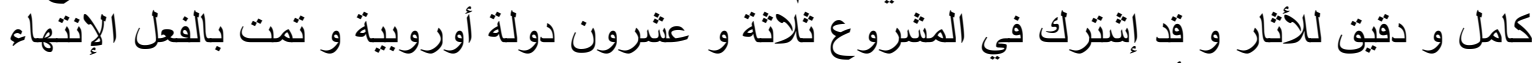

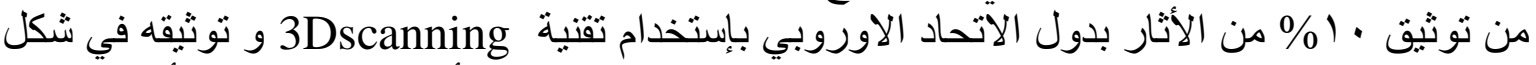
و اقع إفتر اضى يتم الرجوع له عن الأند الحاجة إلي اعمال الاستكمال في الأعمال التي قد تطر أ عليها تلف فئف

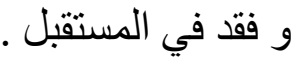

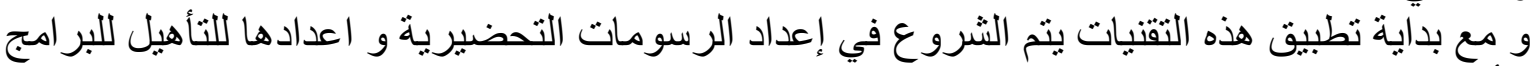

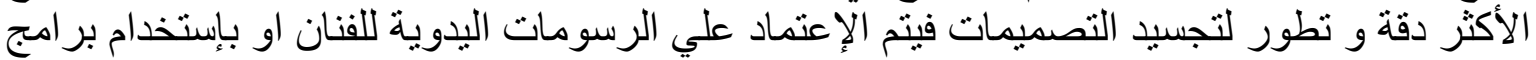

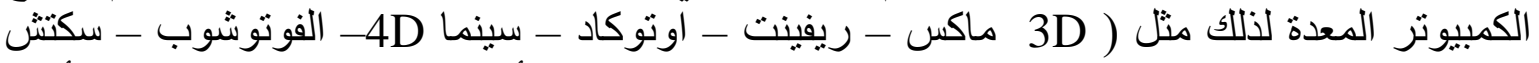
اب) ـ و بعض البر امج المتطورة للنمذجة و النحت البارز ثناثى الأبعاد مثل ل

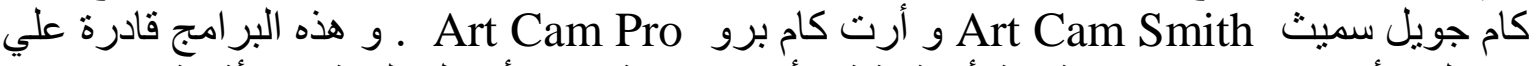
إيصال الأفكار و إتاحتها إما ثنائية أو ثناثية الأبعاد خاصة في في الأعمال الفنية و الأثزية و و إعدادها

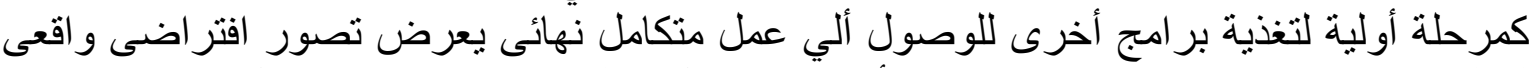

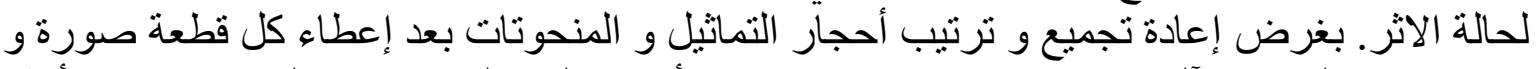

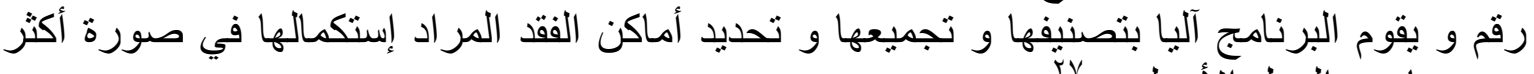

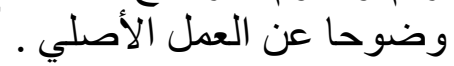


و ينفذ ذلك بالاعتماد علي تقنية الهولوجر ام المسح التصويرى ) Photogrammety and laser

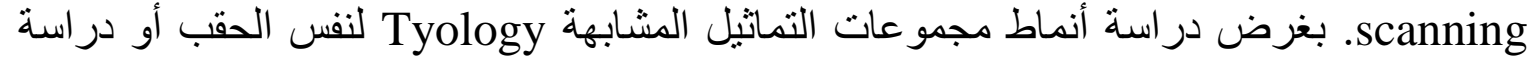

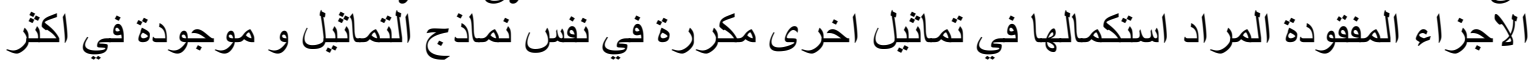

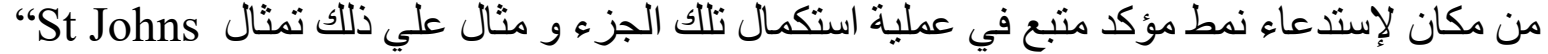
بالمئ Nepomuk

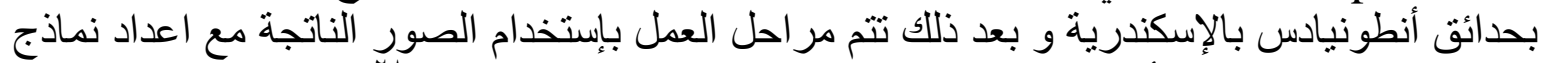

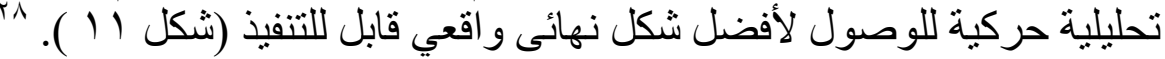

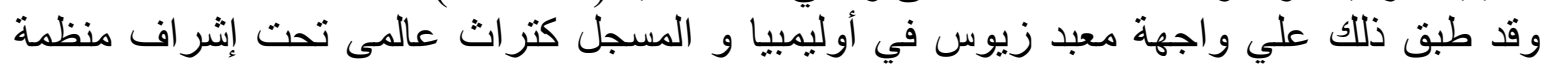

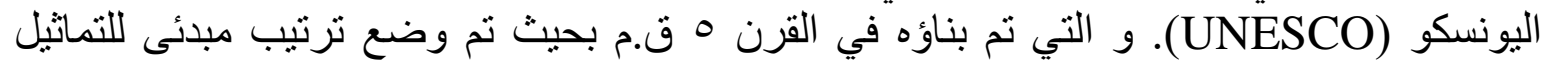

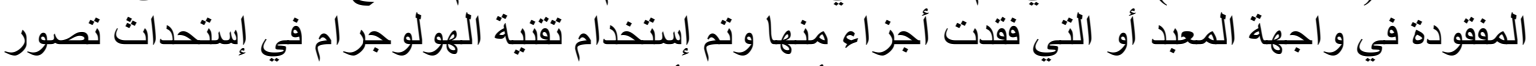
افتراضي بالتبادل لوضع العناصر للوصول لأفضل و أنجح وضع تثريحى و تصميمي مبني علي الني

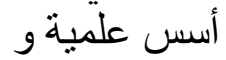

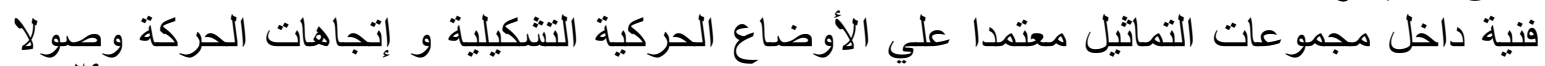

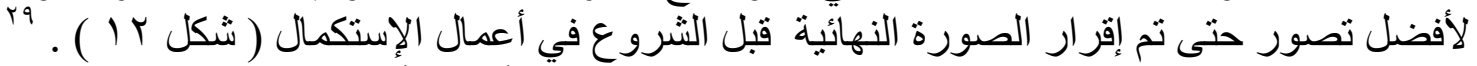

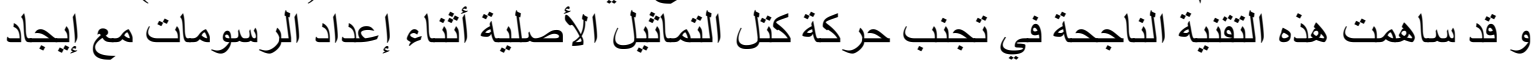

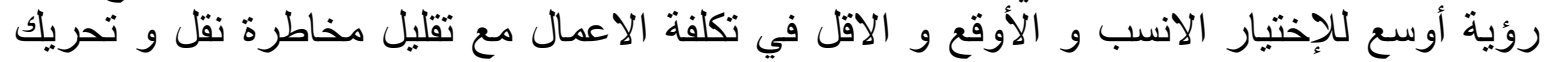

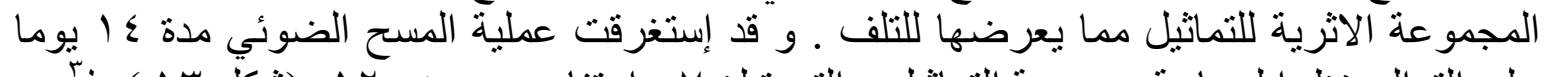

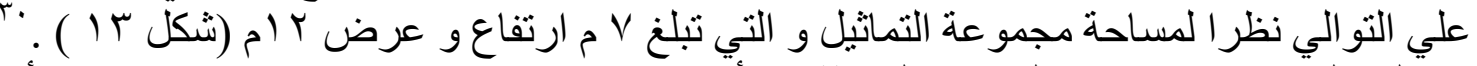

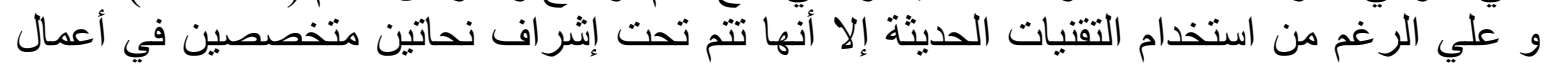

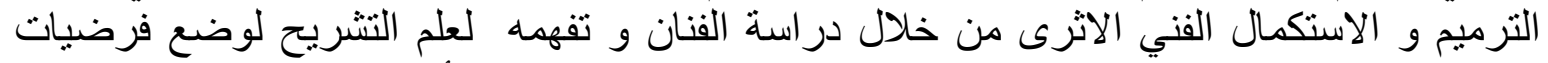

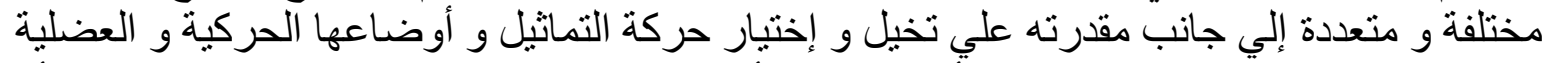

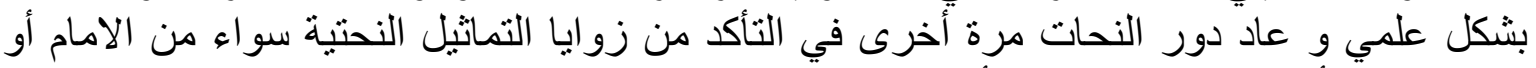

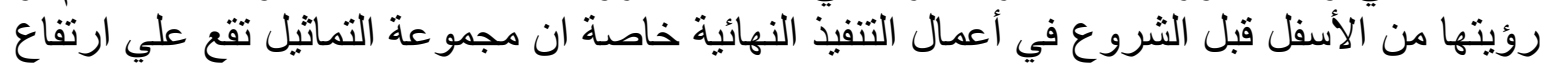

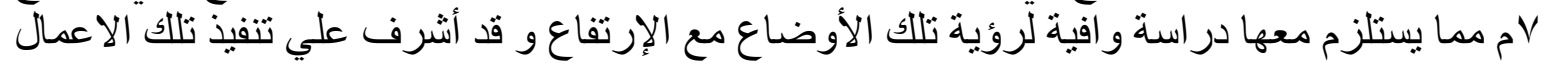

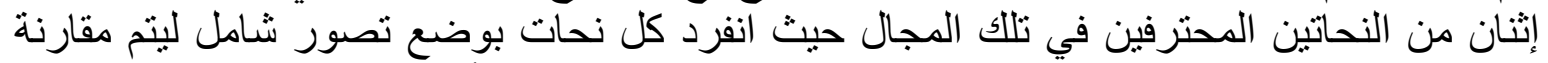

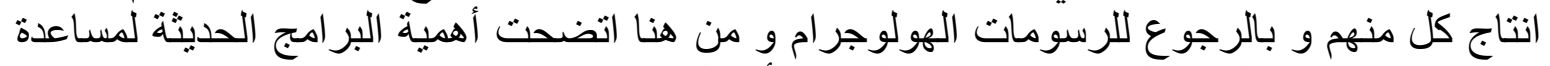

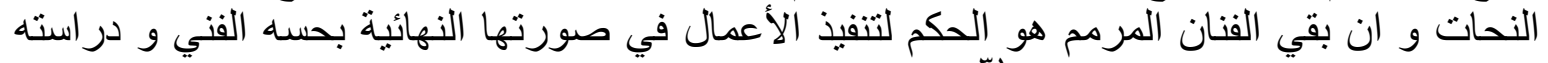

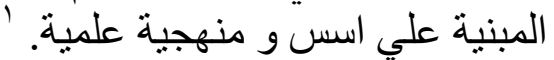

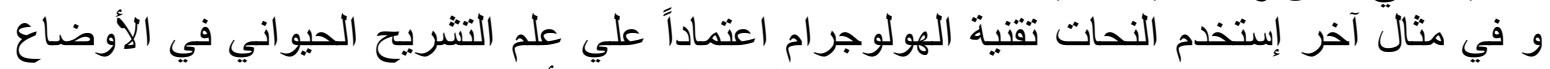

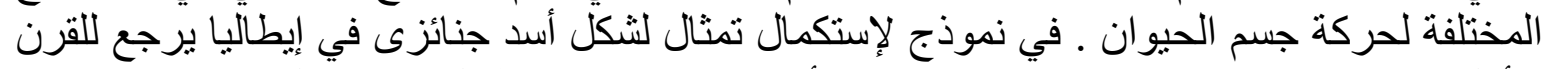

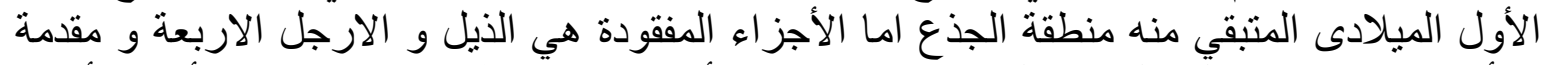

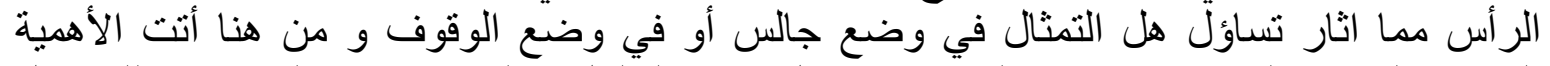

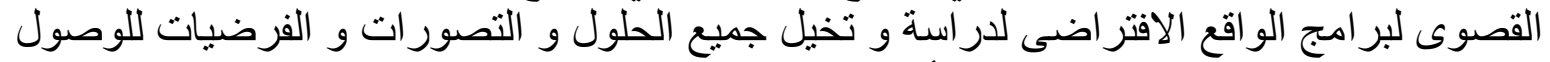

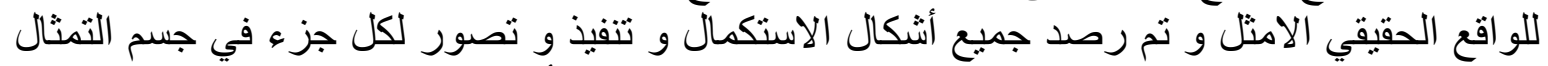

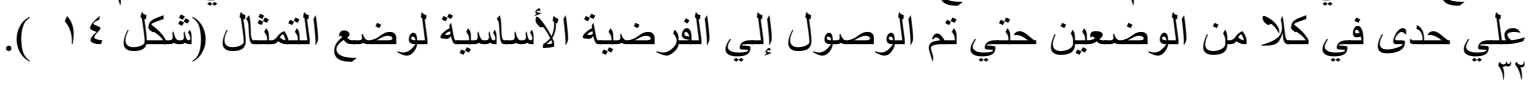

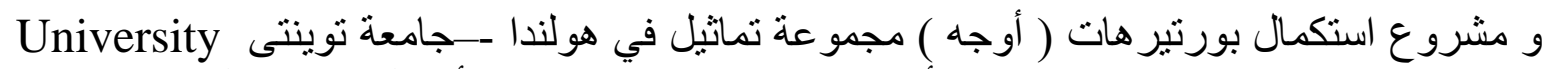

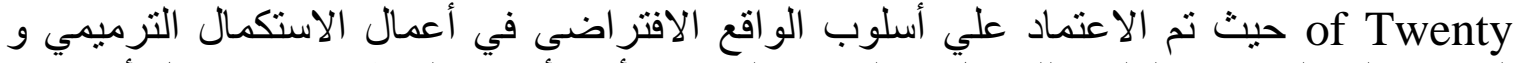

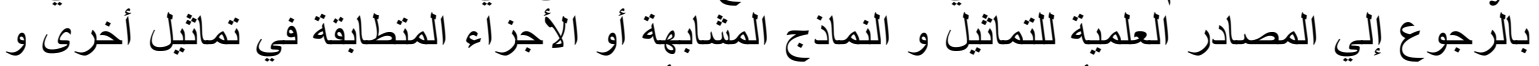

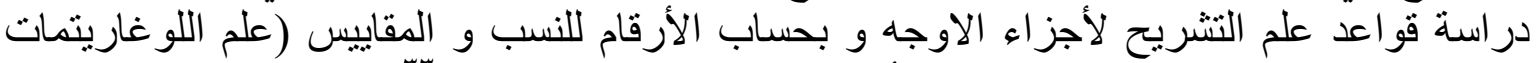

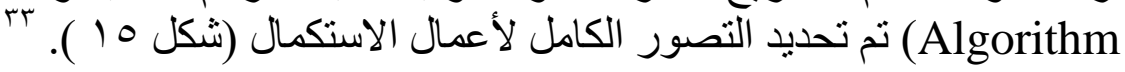




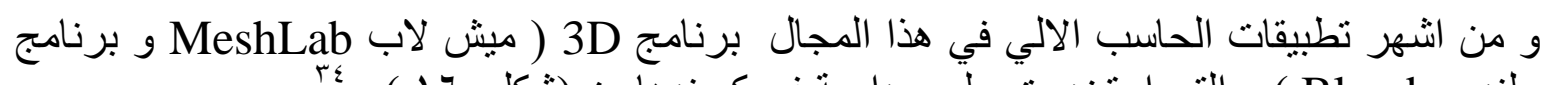

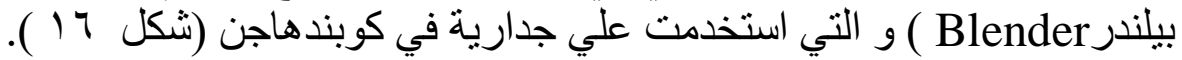

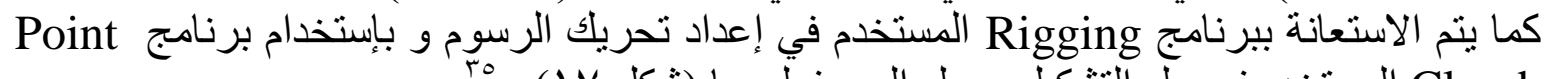

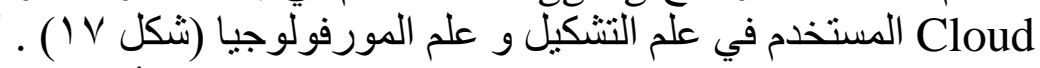

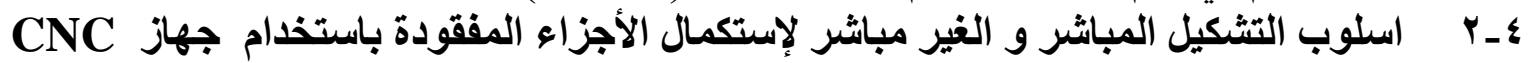

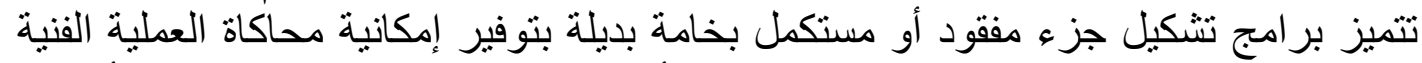

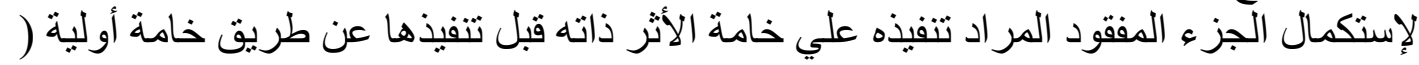

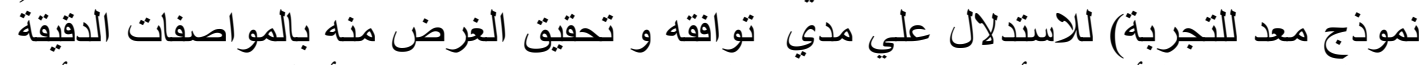

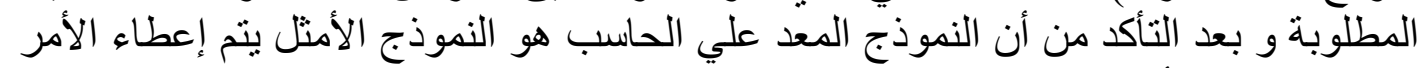

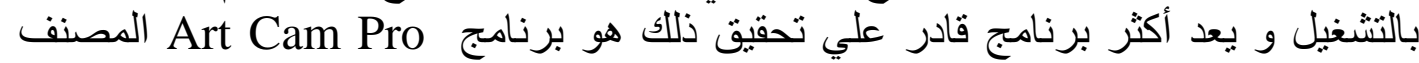

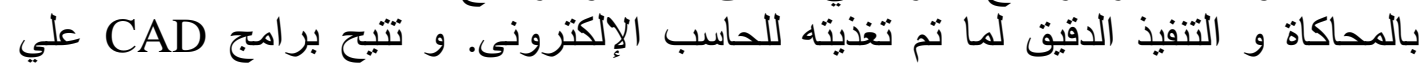

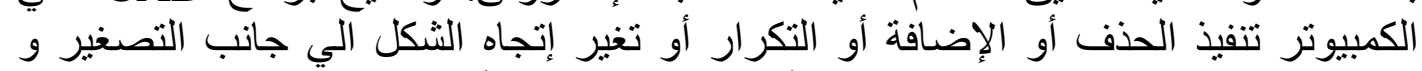

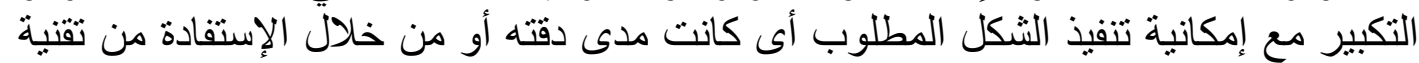

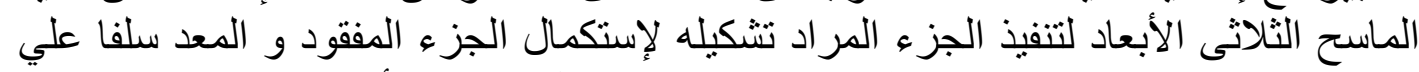

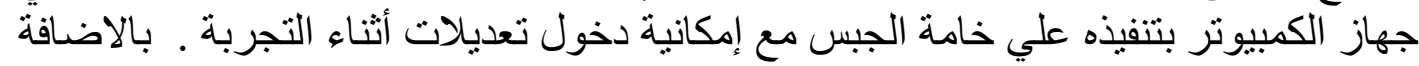

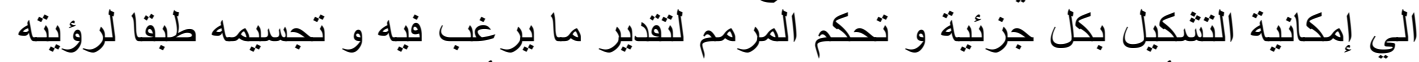

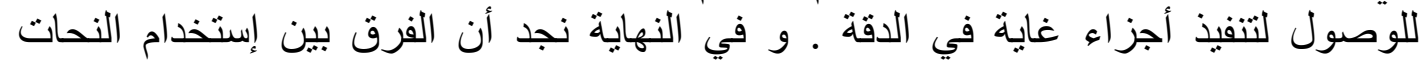

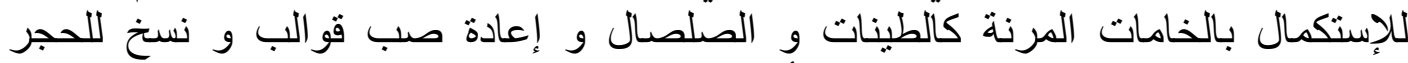

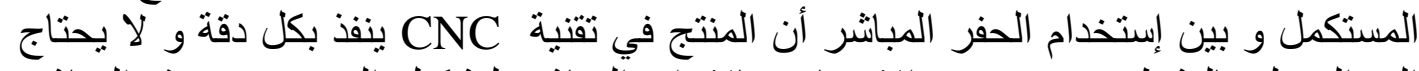

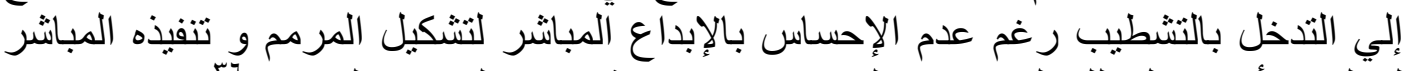

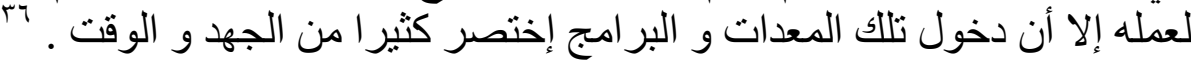

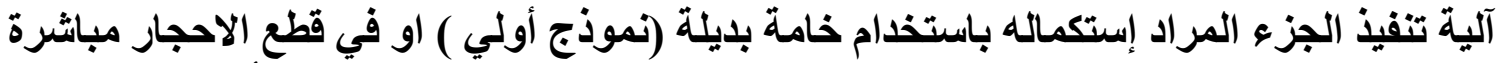

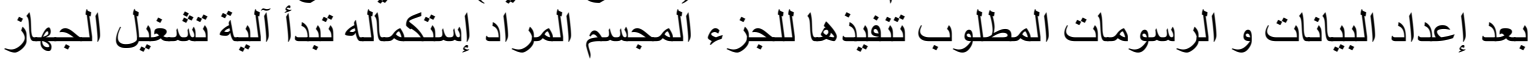

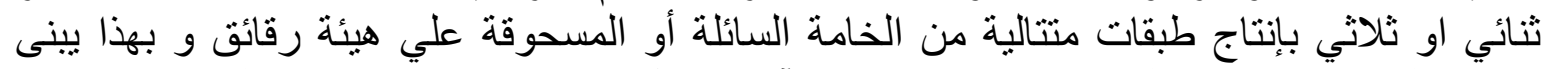

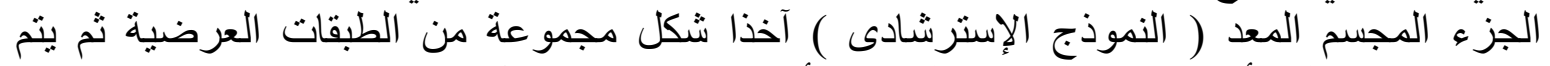

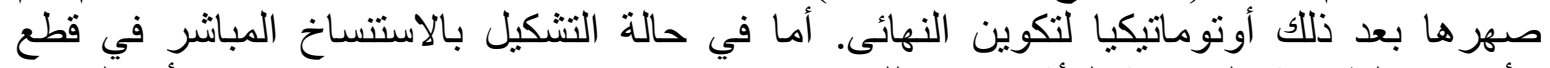

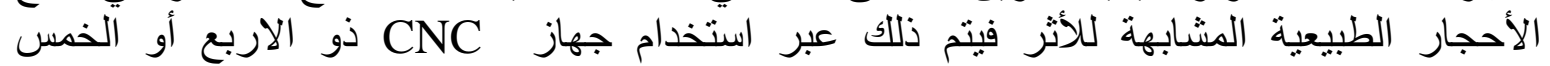

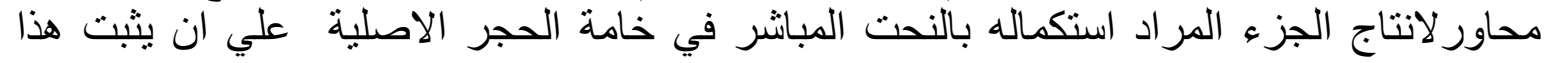
الجزء كاضافة في المكان المر اد استكماله (الجزء المفقود د).

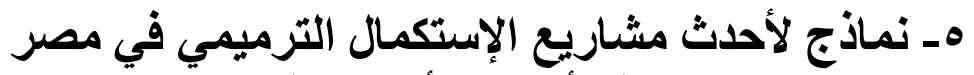

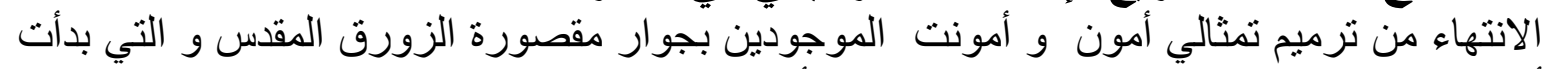

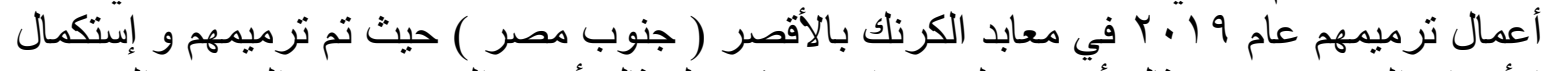

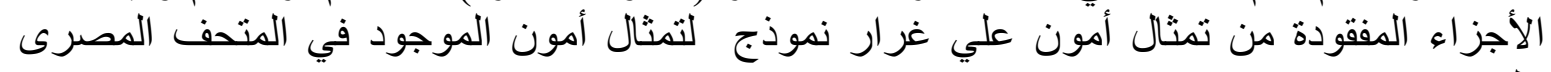

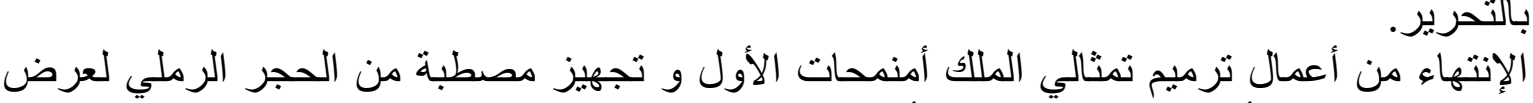

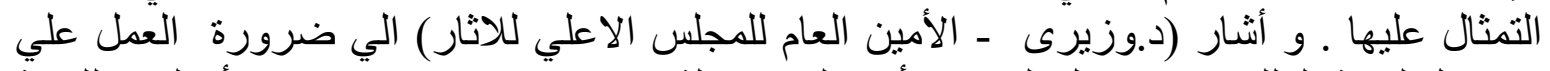

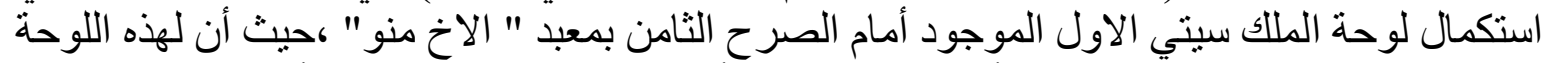

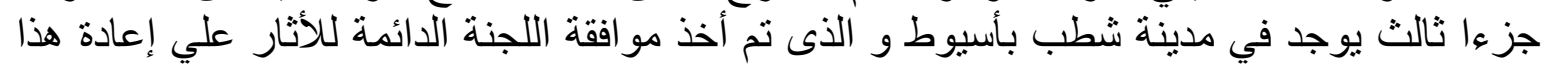

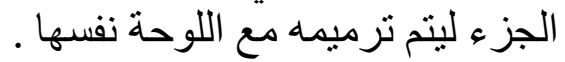




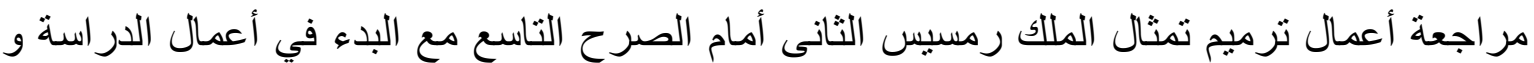

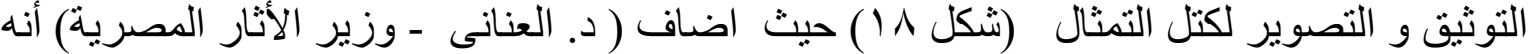

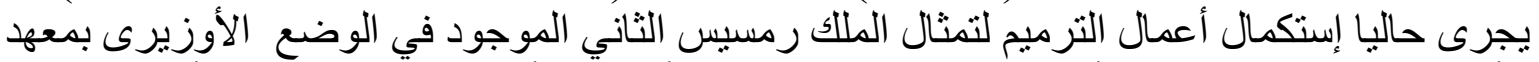

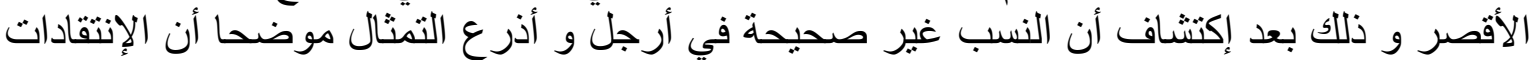

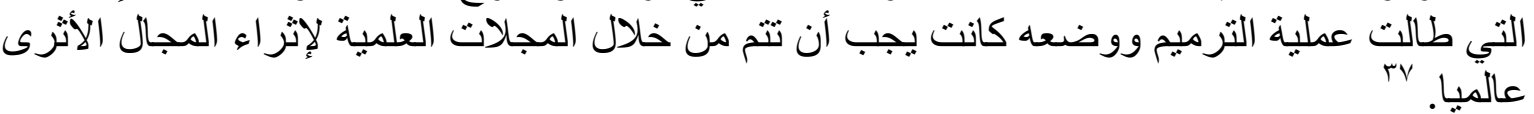

الخلاصة

من خلال عرض البحث و الرجوع للمر اجع العلمية و المصادر و الاسترشادات بالتطبيقات و التجارب العلمية بالمتاحف والمر اكز البحثية و الاكاديمية فى العديد من دول العالم و التي ما تم منها تحت

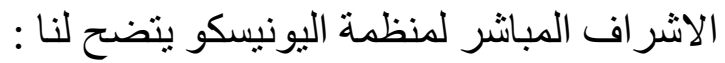
لا غني عن دور الفنان المتخصص في الدراسات الفنية و التشريحية ذات الصلة المباشرة

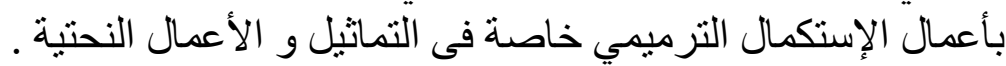

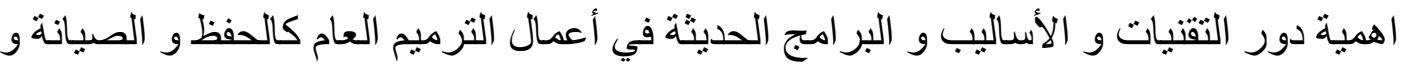

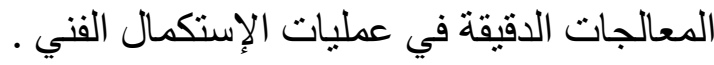
إغفال بعض عمليات الاستكمال خاصة بعض الاجز اء في التماثيل كالاجز اء السفلي أو مر اكز

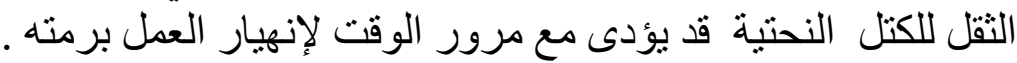

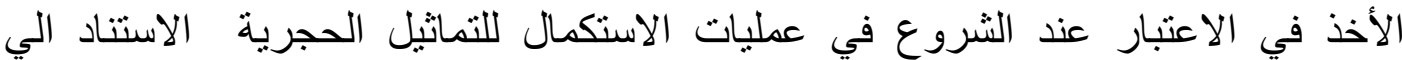

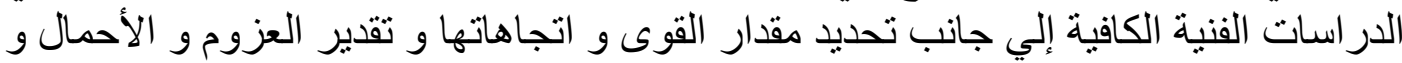

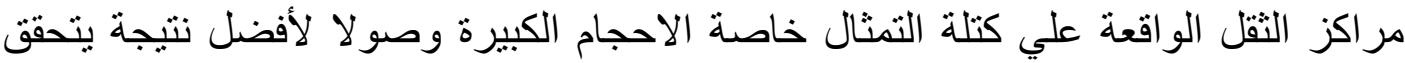
معها الثبات و الاتزان و التماسك البنائى للعمل . التقتيات الحديثة تتو افق في استخداماتها مع المر اكز البحثية و الجامعات الكبيرة نظر ا لتكلفة استخداماتها العالمية.

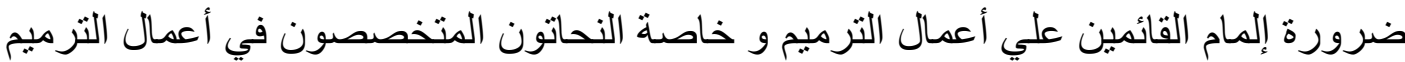
بأحدث التقنيات و البر امج ذات المات الصلة بأعمال الإستكمال الترميمي.

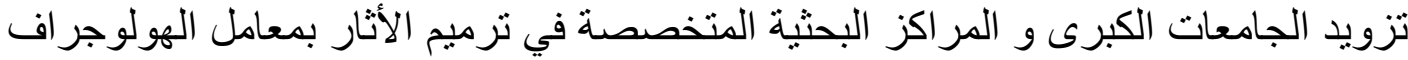
ـ و هو انتاج الصور المجسمة أو الذواكر الهولوغر افية التي تمثلك خاصية فريدة تمكنها من تردئ

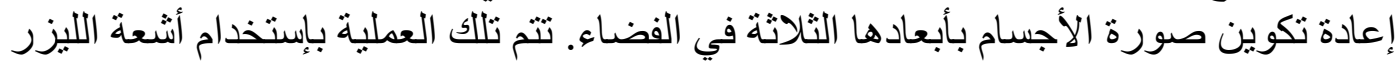

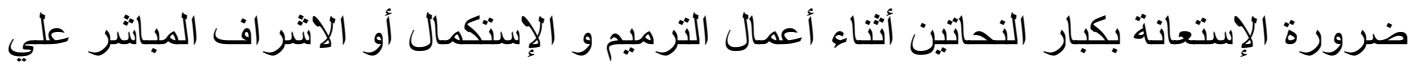

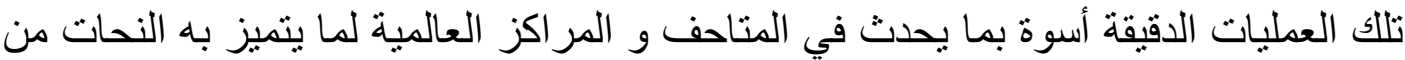

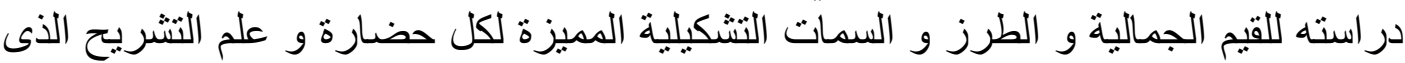

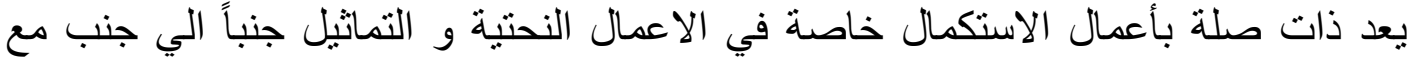

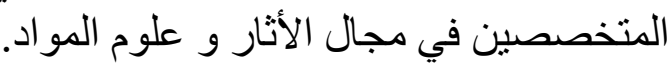
يفضل اعداد البر امج و تجهيز ها بالمعامل و أن تنفذ أعمال الاستكمال الترميمي للأثنار في الأني مو اقعها قدر الامكان و الاتنقل إلا في حال الضرورة القصوى . 


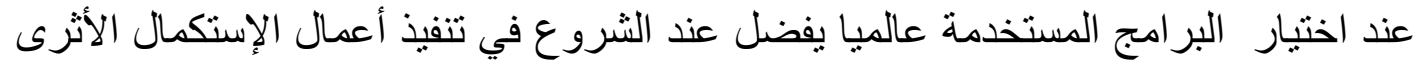

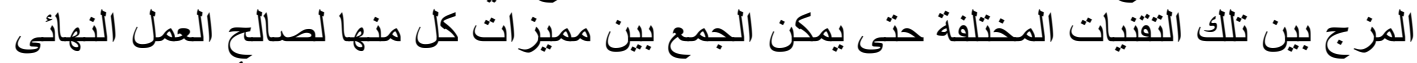

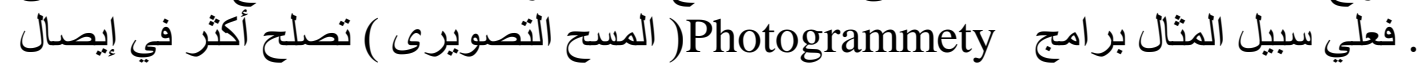

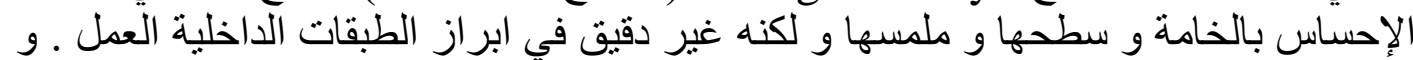

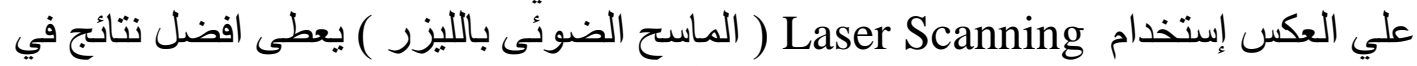

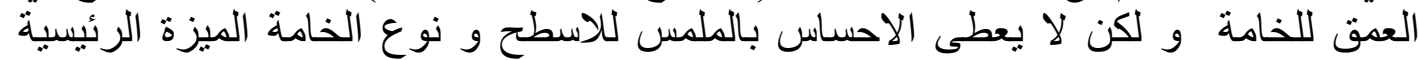

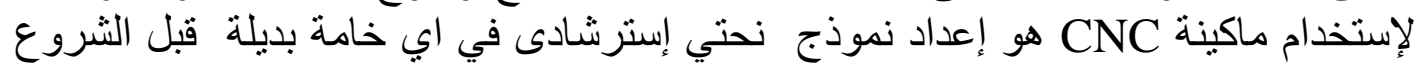

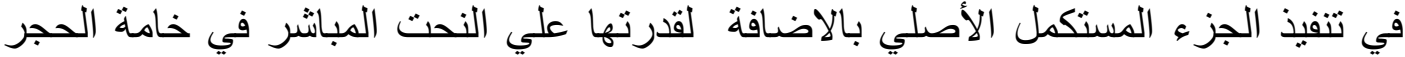

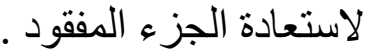

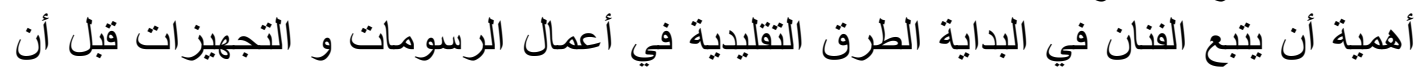

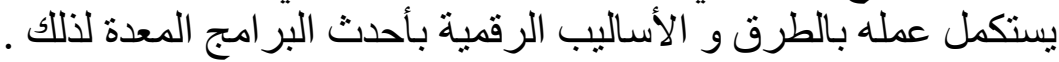

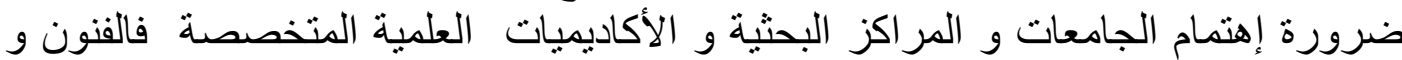

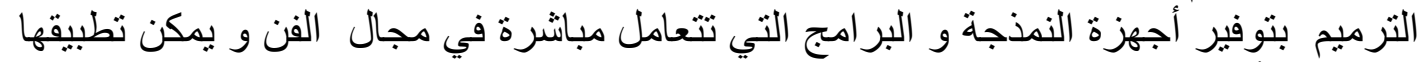

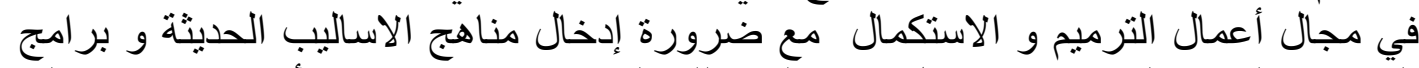

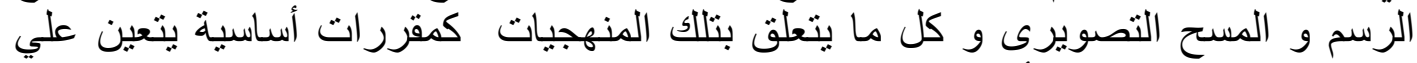

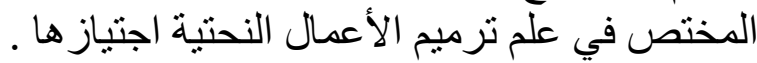




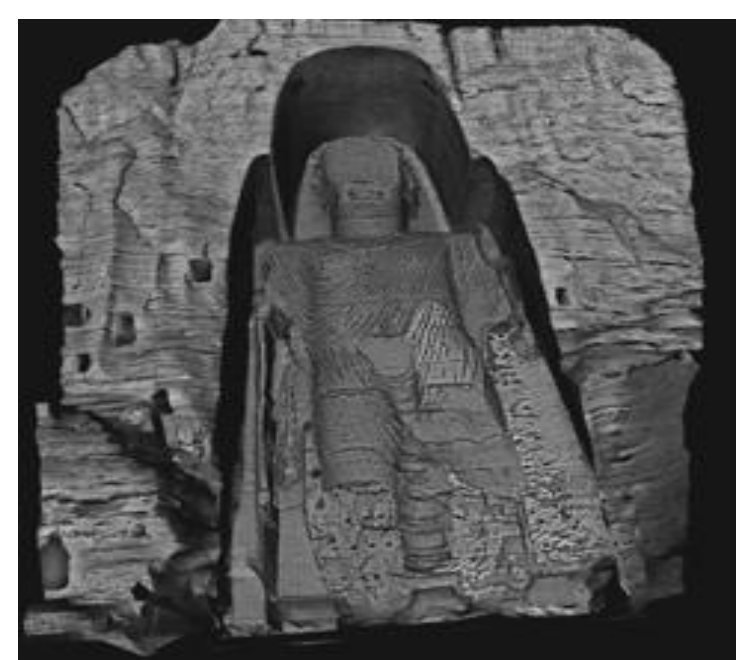

الاستكمال الافتر اضي

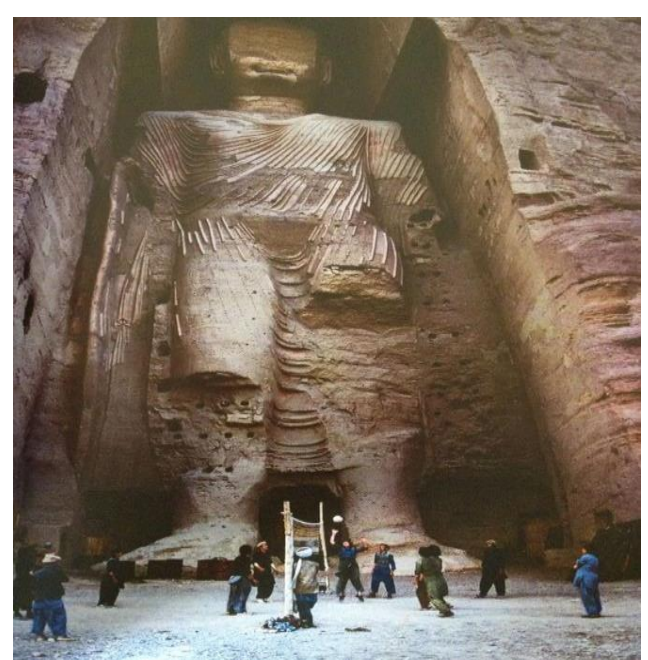

تمثال بوذا- جبل باميان / افغانستان بعد التدمير بالاسلحة الثقيلة

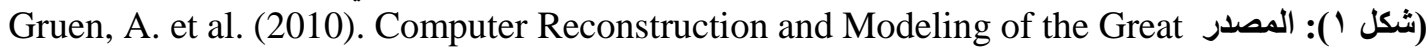

Buddha Statue in Bamiyan, Afghanistan

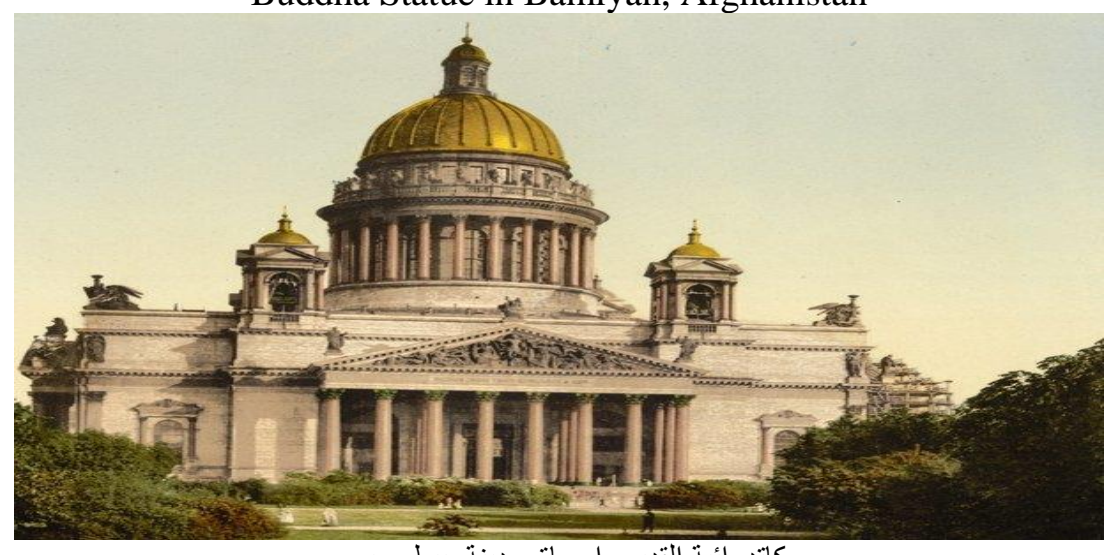

كاتدر ائية القديس اسحاق مدينة بيطرسبرج

Gnezdilov, D. et al (2019). The Problem of Preservation, Restoration, and (شكل ץ): المصدر Reconstruction of the World Architectural Heritage

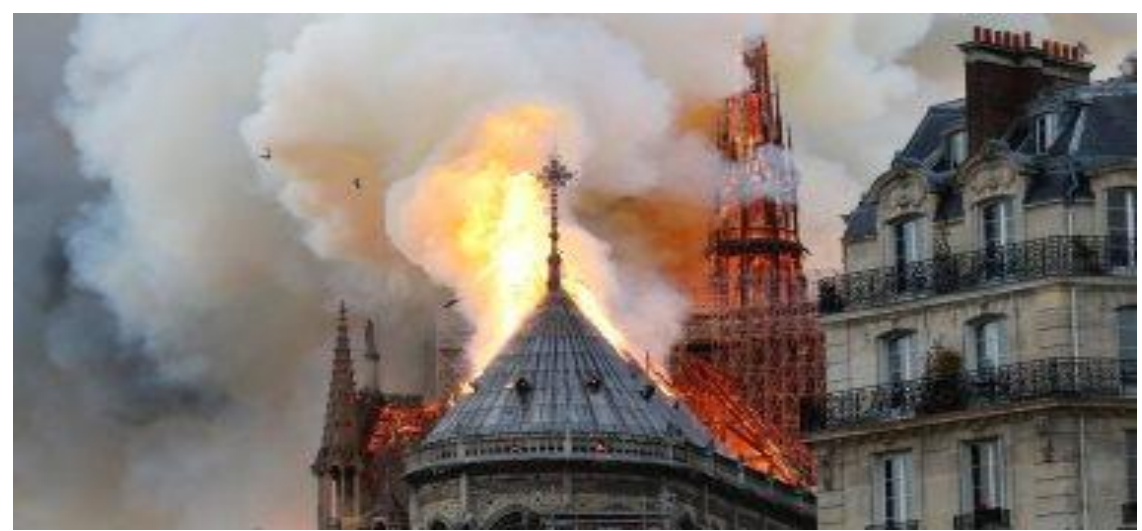

حريق كاتدر ائية نوتر دام مدينة باريس

Gnezdilov, D. et al (2019). The Problem of Preservation, Restoration, and المصدر Reconstruction of the World Architectural Heritage 


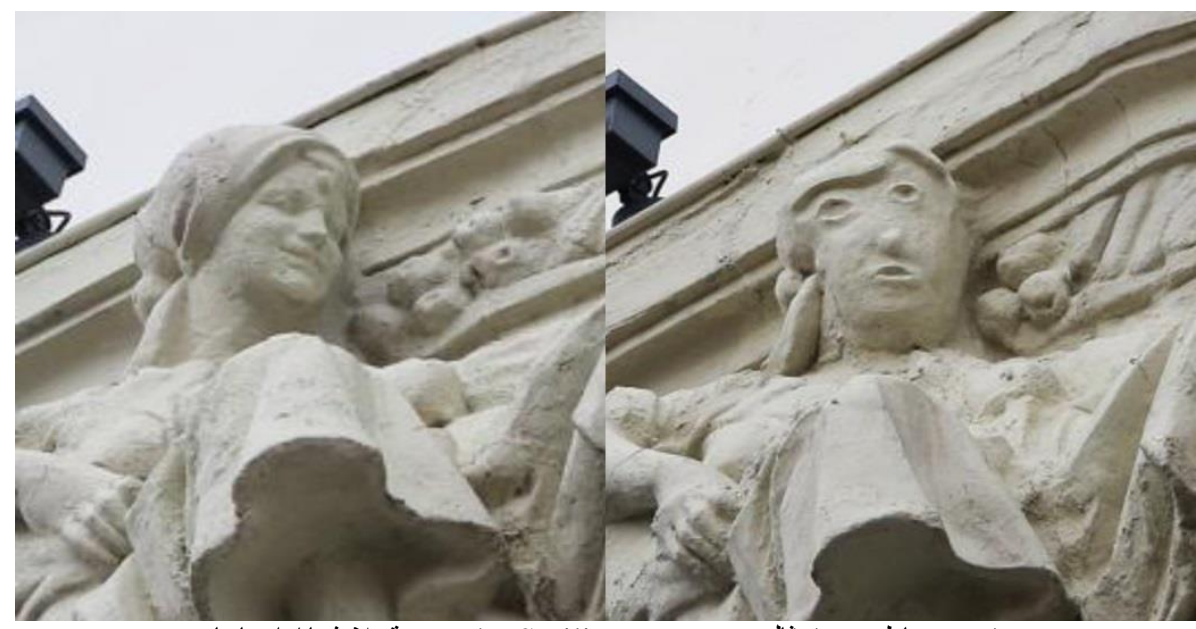

ترميم خاطيء - تمثال The Smiling Woman مدينة بلانشيا / اسبانيا

Davis, I., (2020). Botched Art Restoration in Spain Renders Smiling Statue (شكل ؛) : المصدر Unrecognizable

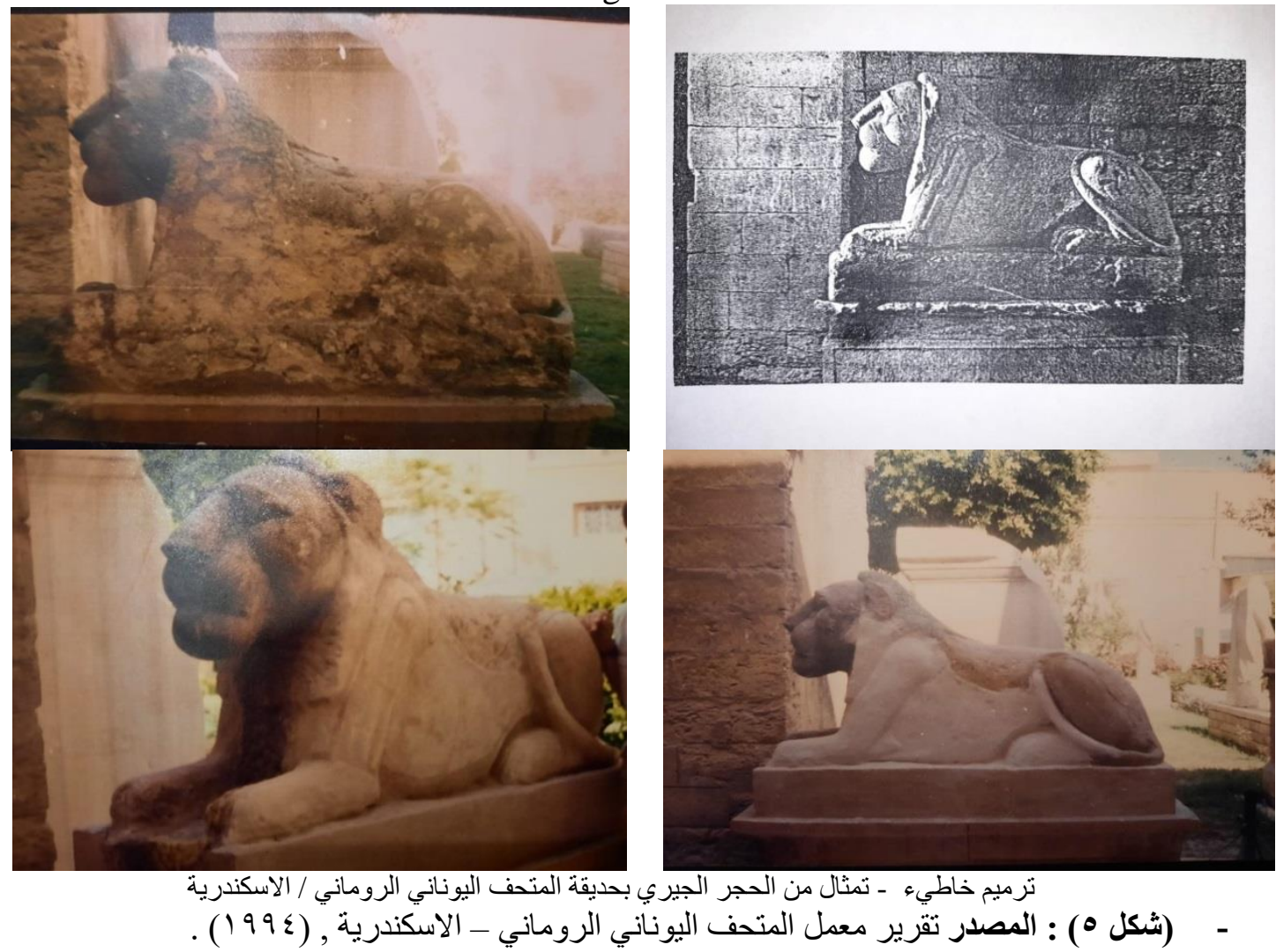



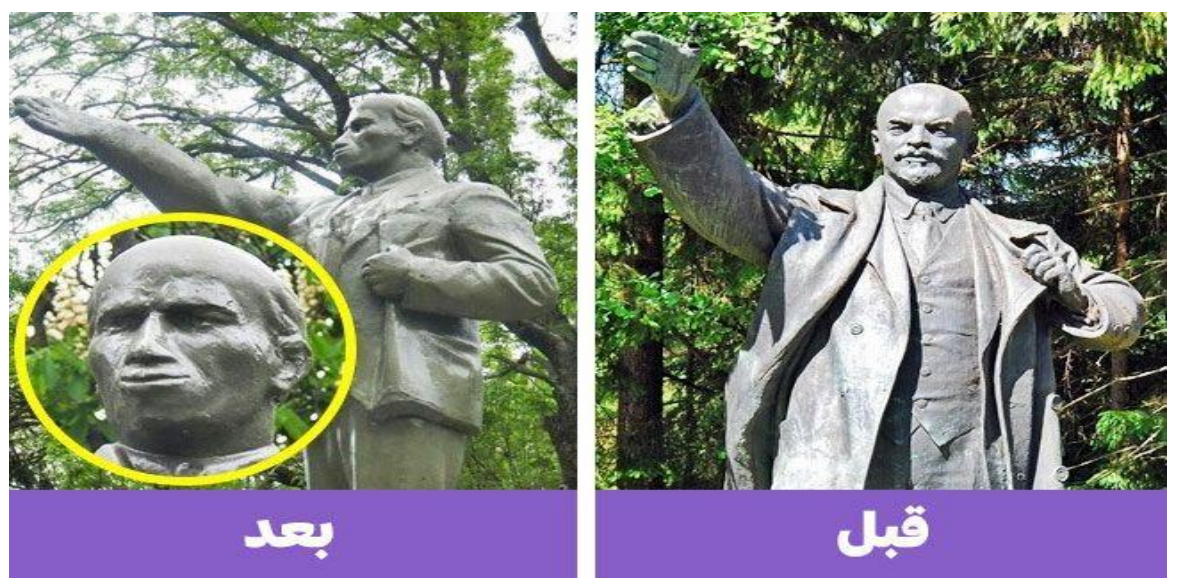

ترميم خاطيء - وتمثال للرئيس السوفييني "لينين" في مدينة ”كر اسنودار كراي “ / روسيا

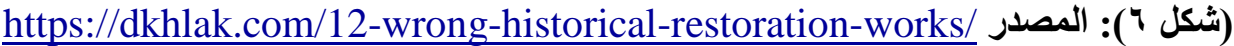

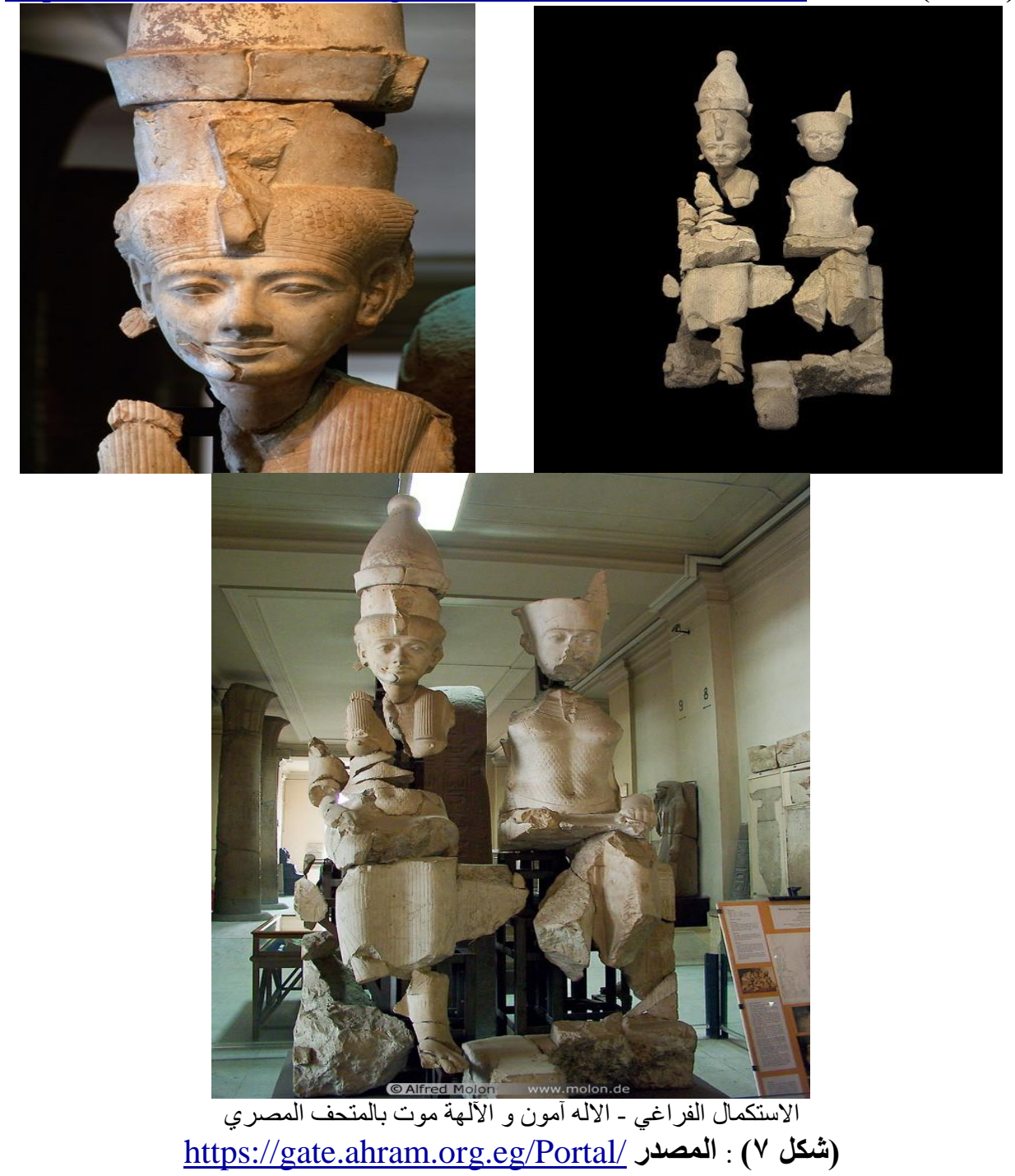



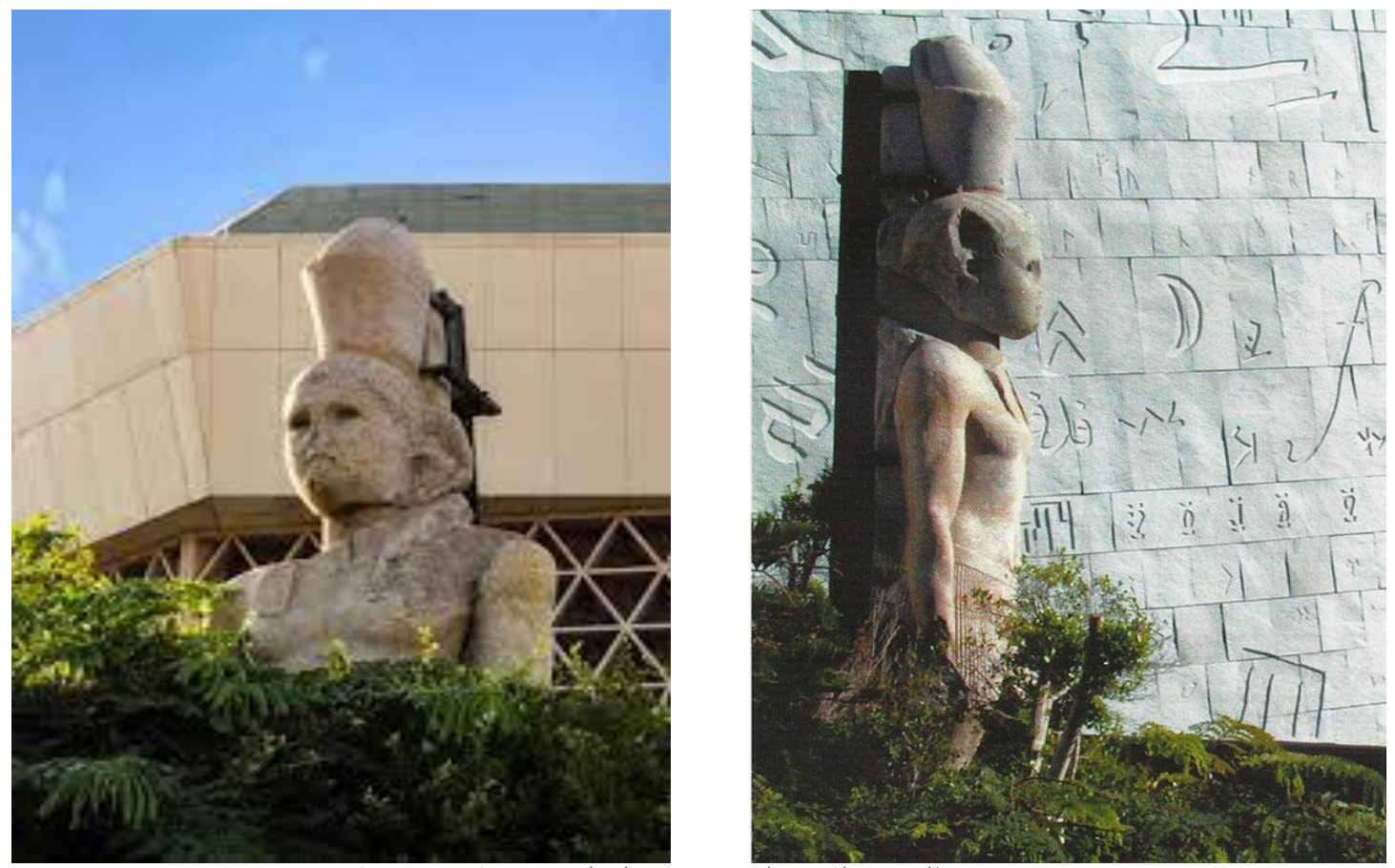

بطليموس الثاني علي قاعدة من الصلب - مكتبة الاسكندرية

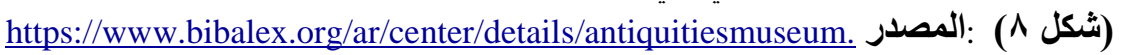
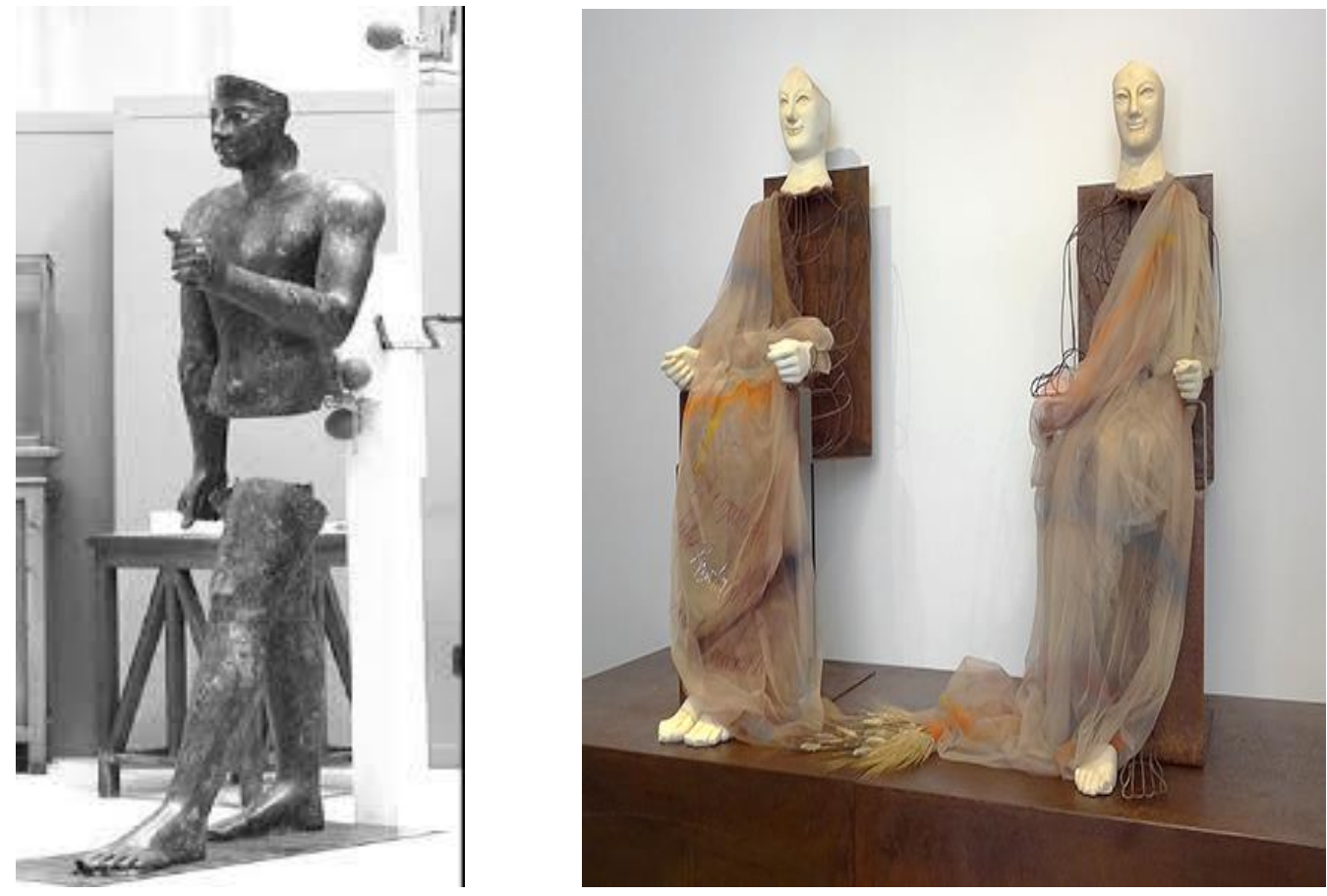

الفرعون بيبي الاول

The Acrolithic Statues of Demeter and Kore

: Rosewitz, J., et al (2016). Use of magnets for reversible restoration in sculpture: (شكل 9 (ش) the case of the "Virgin de los Desamparados 


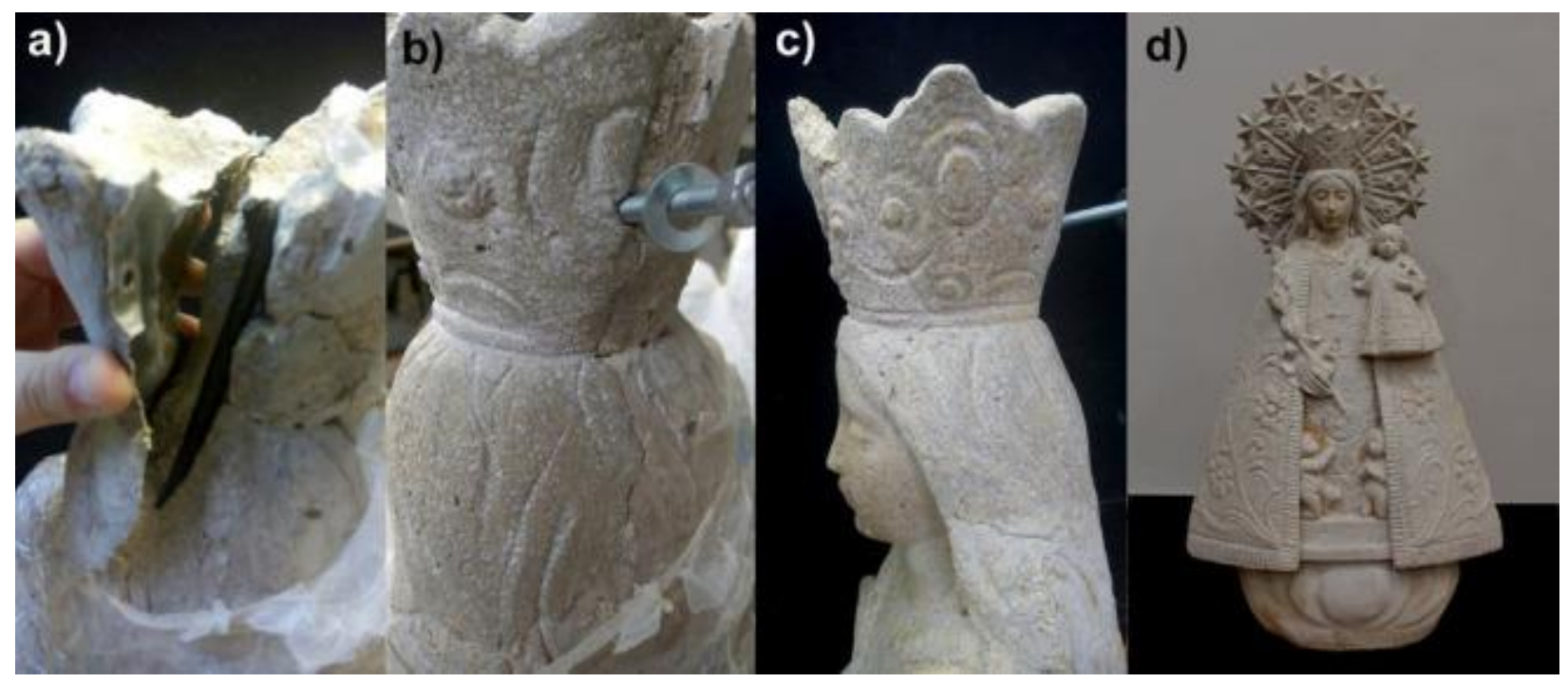

Virgin de los Desamparados الاستكمال باستخدام المغناطيس و المعدن - تمثنال

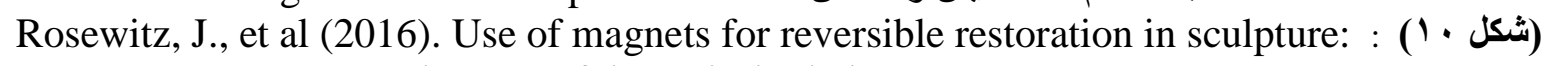
the case of the "Virgin de los Desamparados
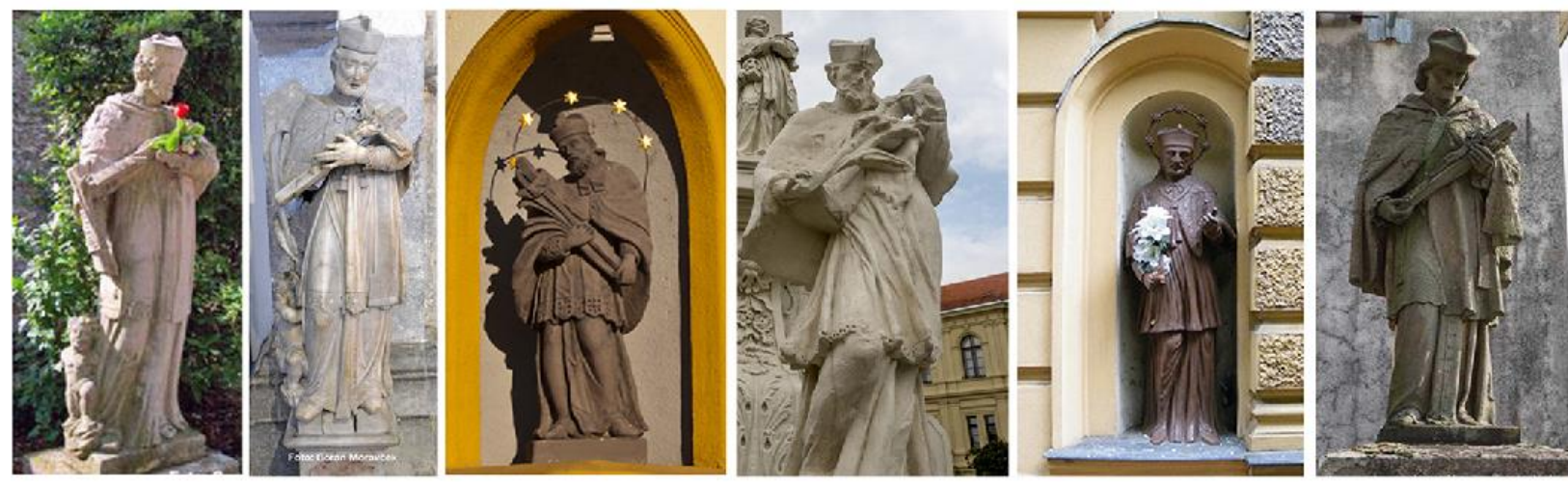

تمثال القديس St Johns Nepomuk بجمهورية صربيا - مجمو عات التماثيل المشابهة Typology

a)

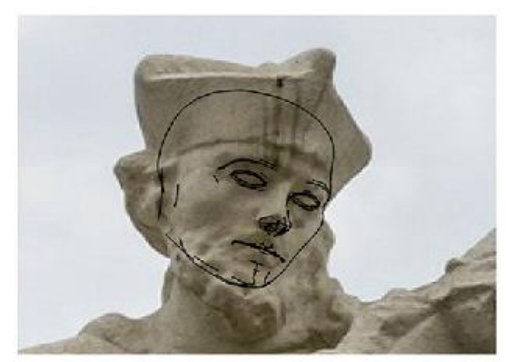

b)

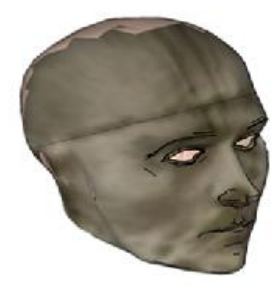

c)

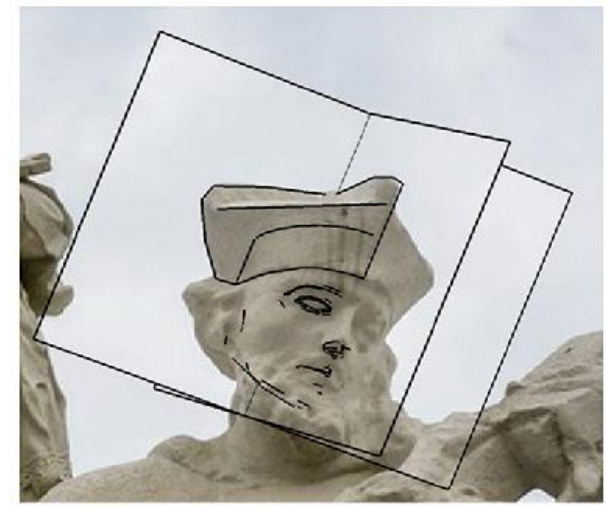

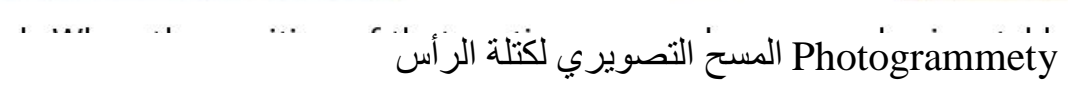

Vesna, S.et al (2018). Parametric Modeling Applied to the Virtual Reconstruction of the : (شكل 11) Damaged Sculpture of St. John Nepomuk in Petrovaradin 

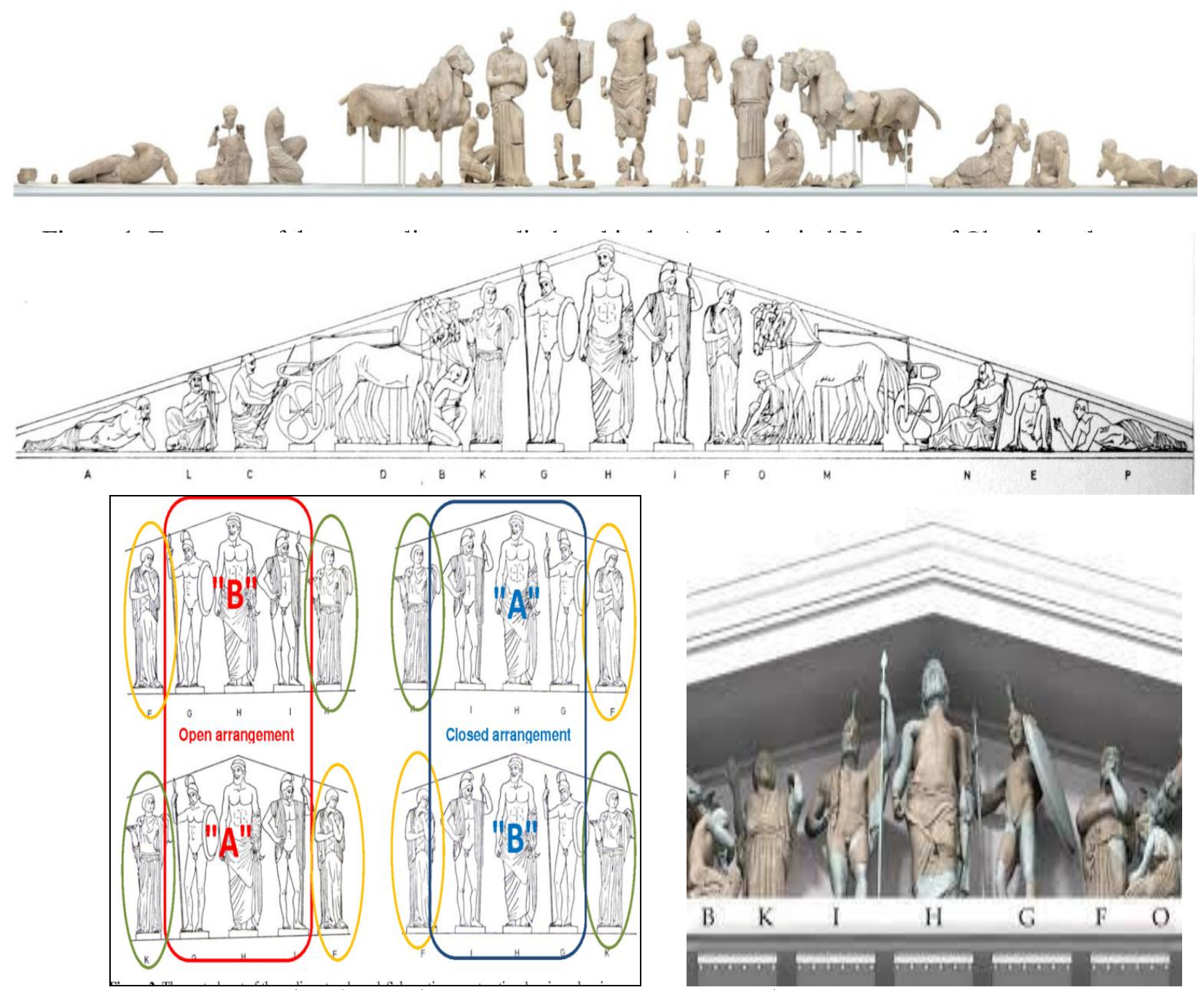

واجهة معبد زيوس - اوليمبيا حيث تم وضع أكثر من تصور لترتيب التماثيل

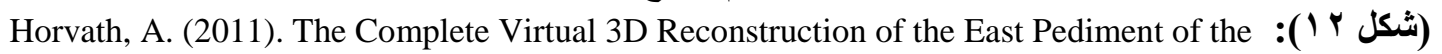
Temple of Zeus at Olympia

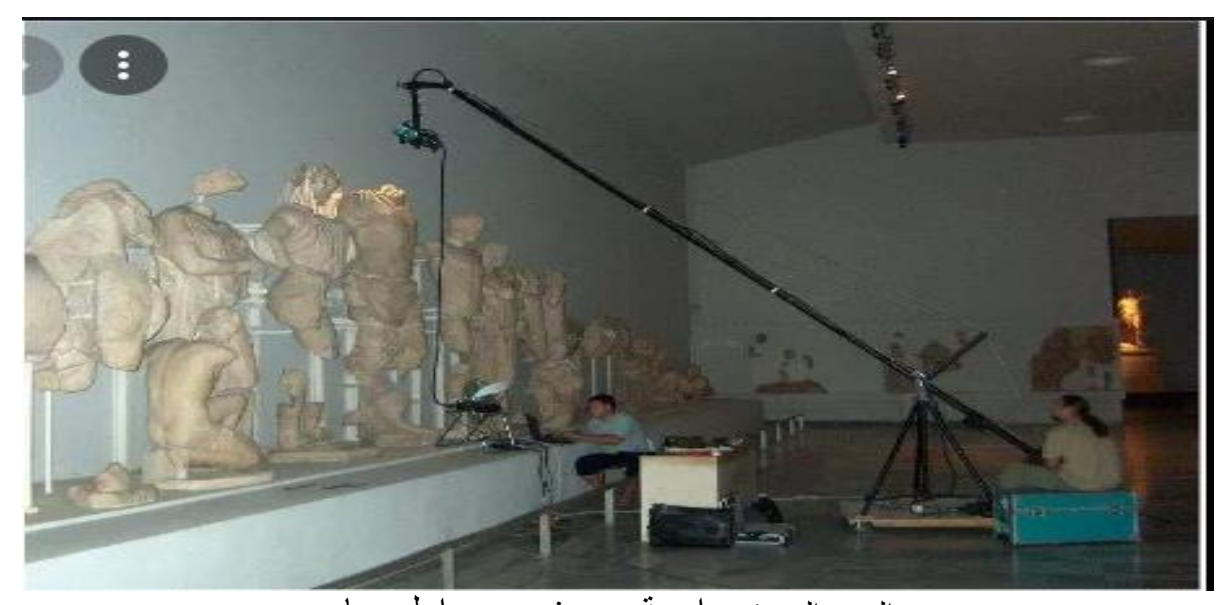

المسح الضوئي و اجهة معبد زيوس - اوليبمبيا

https://123dok.com/document/ye9pk8rq-isprsarchives-xxxviii-w.html - شكل زبوس 1 ( ) : المصدر 


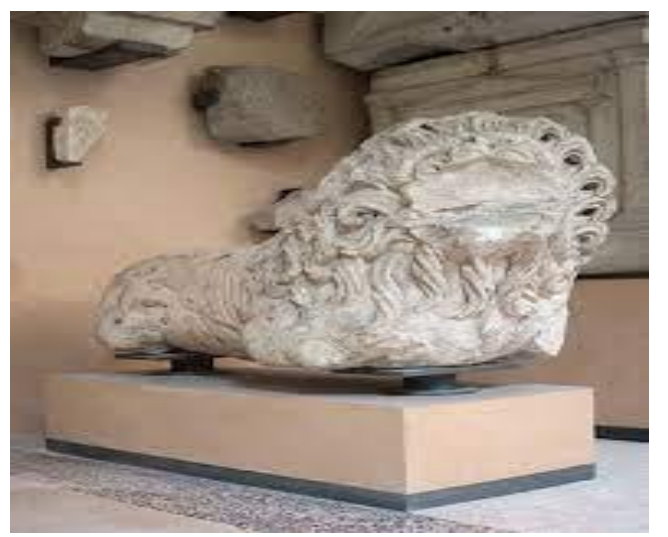

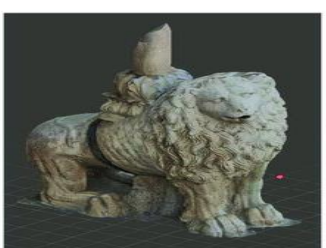

a

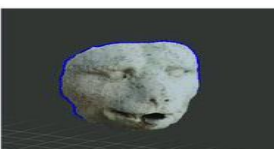

c

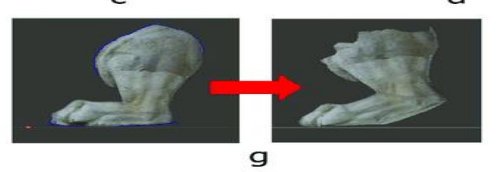

ستخدام الهولوجر ام و علم التثريح الحيو اني لاستكمال الأجزاء المفقودة من اسد جنائزي - ايطاليا

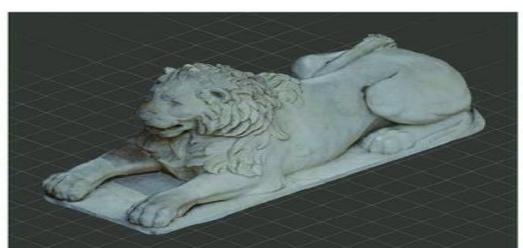

b

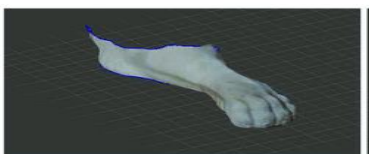

d

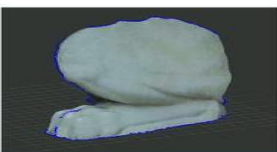

e

f

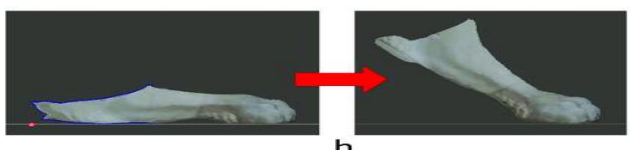

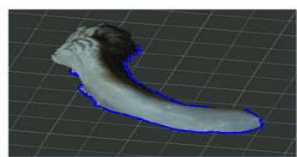

(شكل \& 1 ): المصدر Visualization of Damaged Stone Sculptures
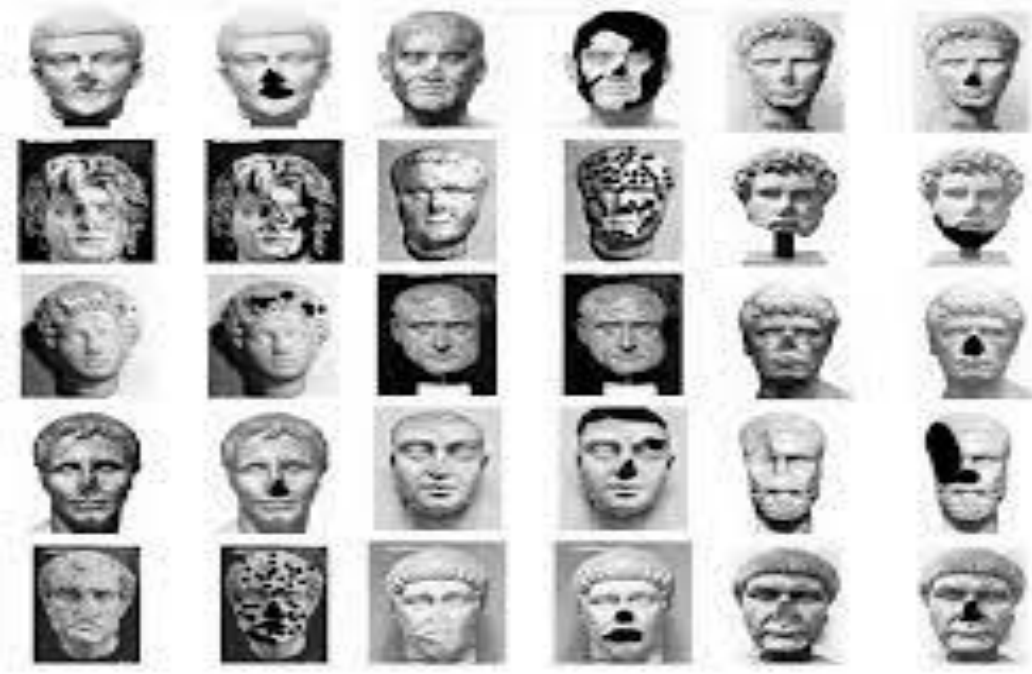

استخدام الهولوجر ام و علم التثريح لاستكمال مجمو عة بورتريهات - جامعة توينتي في هو لندا

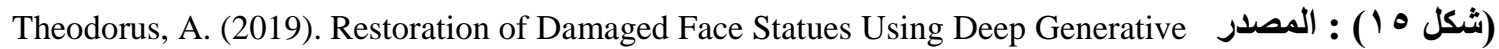
Inpainting Model 


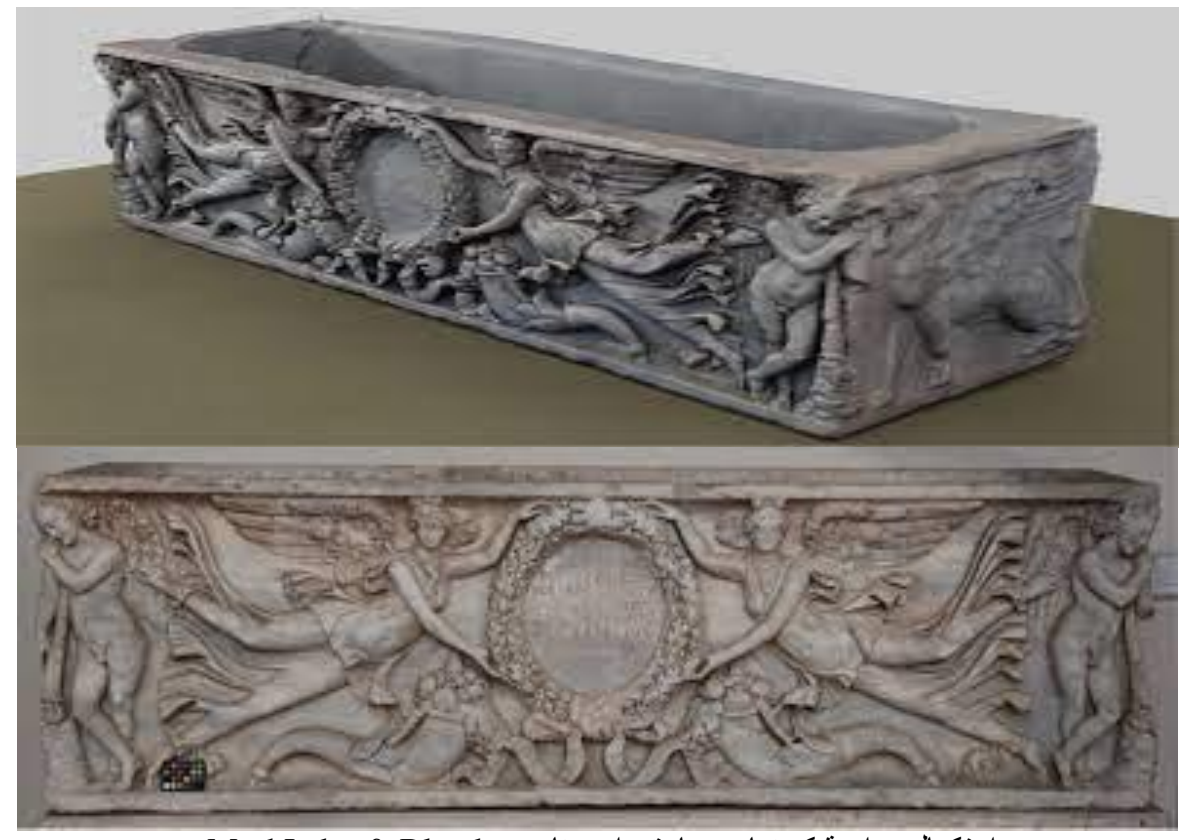

MeshLab \& Blender استكمال جدارية كوبنهاجن ياستخدام برنامج

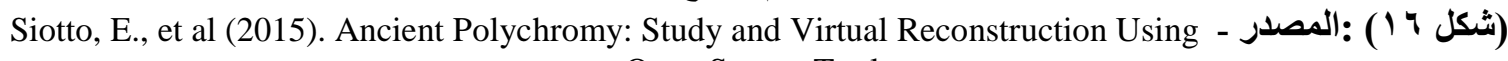
Open Source Tools
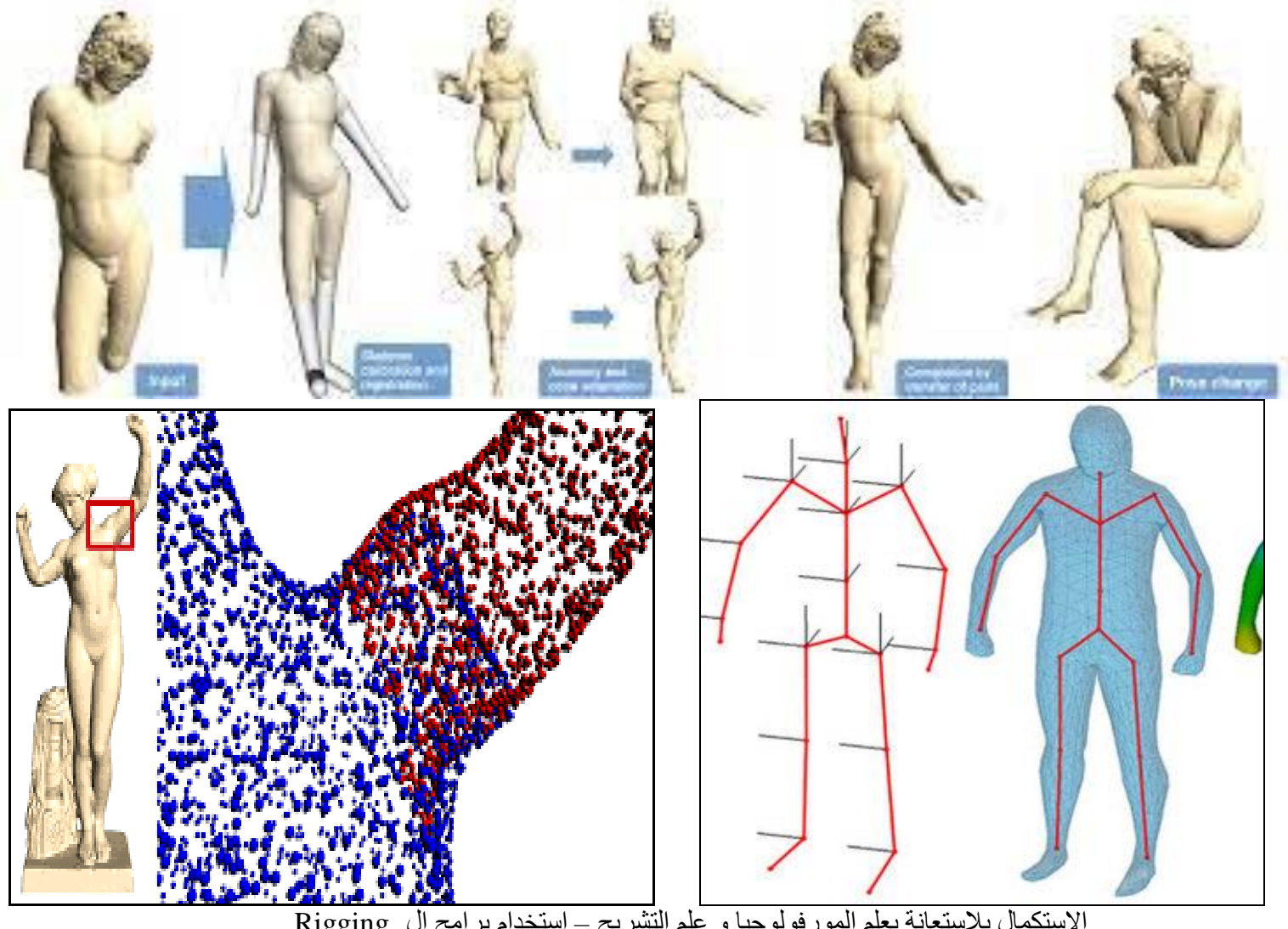

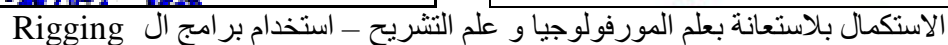

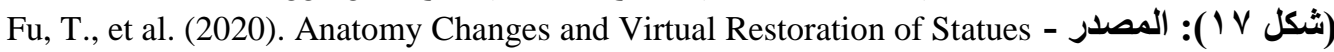



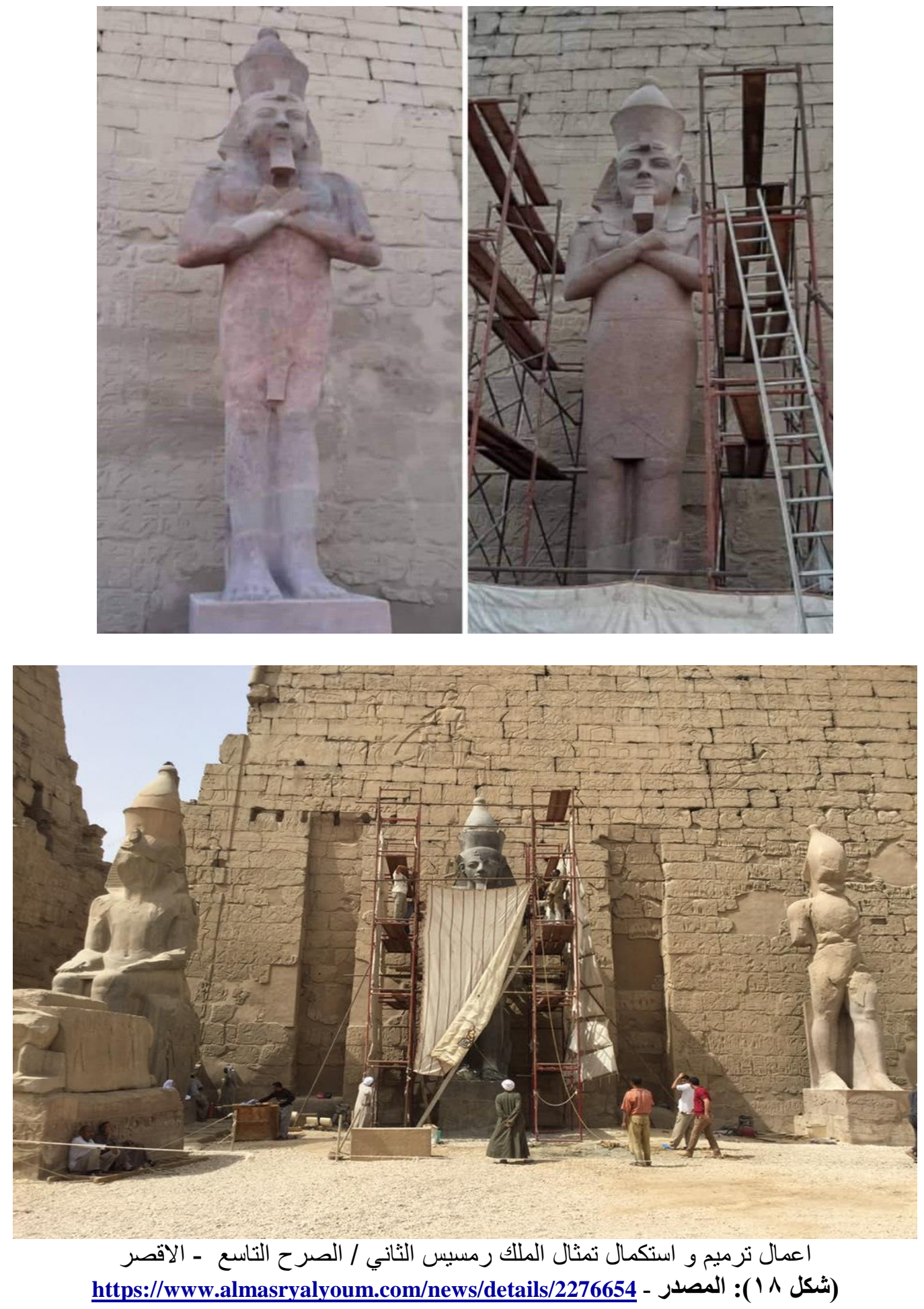


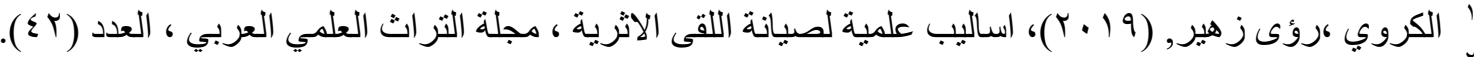

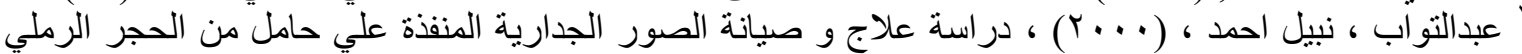

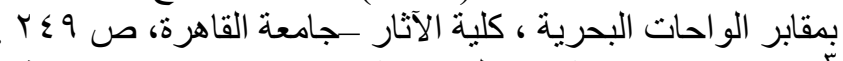

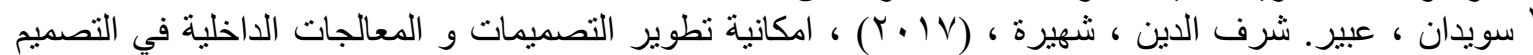

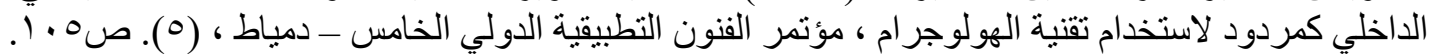

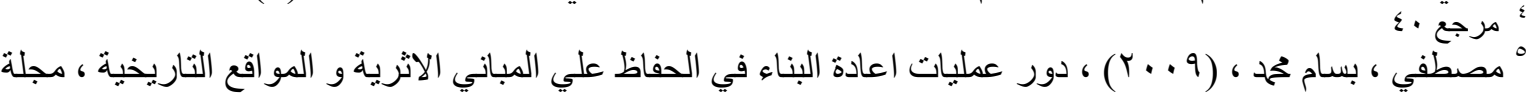

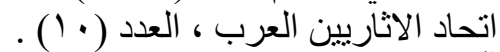

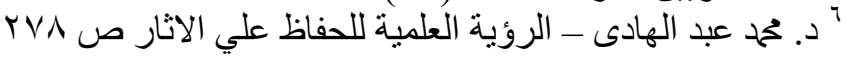

${ }^{7}$ Brutto, M. and Fazio, L. (2021). An Experimental Workflow for the Virtual Reconstruction of Ancient Statues. Conference paper.

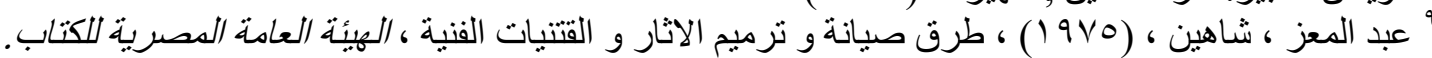

${ }^{10}$ Gruen, A., Remondino, F. and Zhang, L. (2010). Computer Reconstruction and Modeling of the Great Buddha Statue in Bamiyan, Afghanistan, International Archives of Photogrammetry and Remote Sensing, 64 (5).

${ }^{11}$ Gnezdilov, D., Kapnina, E. and Martynyuk, E. (2019). The Problem of Preservation, Restoration, and Reconstruction of the World Architectural Heritage. IOP CONFERENCE: Materials Science and Engineering, (698).

r' المحاري،سلمان , حفظ المباني التاريخية ، المركز الدولي لدراسة صون وترميم المثنكات الثقافية ، الامارات

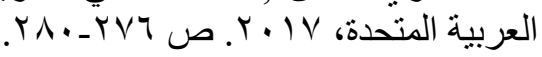

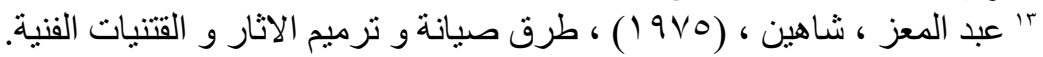

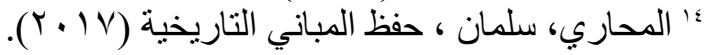

${ }^{15}$ Davis, I., (2020). Botched Art Restoration in Spain Renders Smiling Statue Unrecognizable, Smithsonian Magazine, November, 12.

${ }^{17}$ https://dkhlak.com/12-wrong-historical-restoration-works/

$$
\text { 14 تقرير معمل المتحف اليوناني الروماني ـ الاسكندرية ، ( } 99 \text { (1) ). }
$$

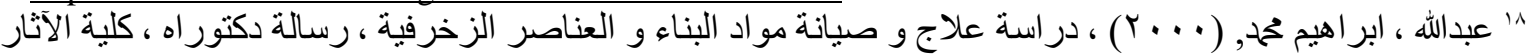

${ }^{19}$ Mora, P. and Torracoa, G. (1984). Grouting of Mural Printing and Mosaics Adhesives, Oxford Print, pp.115-116.

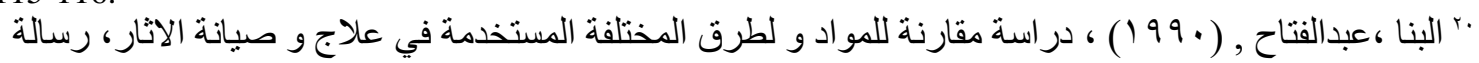

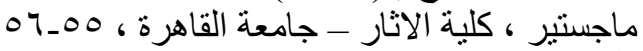

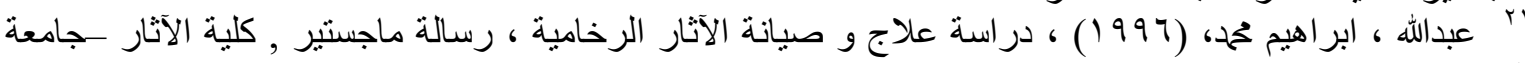

${ }^{22}$ https://www.bibalex.org/ar/center/details/antiquitiesmuseum. القاهرة.

${ }^{23}$ Rosewitz, J., Muir, C., Riccardelli, C. and Rahbar, N. (2016). Use of magnets for reversible restoration in sculpture: the case of the "Virgin de los Desamparados", Materials \& Design, 98.

${ }^{24}$ https://technologyreview.ae/technodad/85

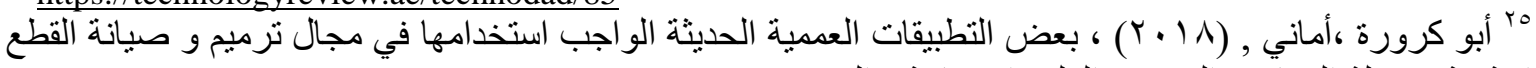

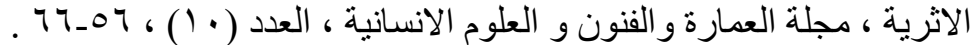

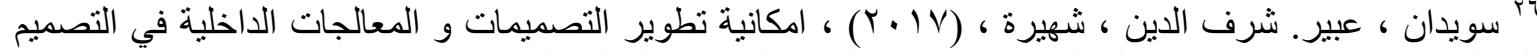

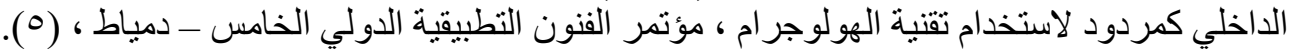

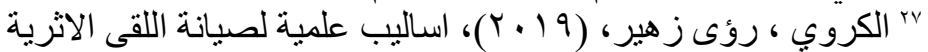


${ }^{28}$ Vesna, S., Budak, I. and Obradovic, R. (2018). Parametric Modeling Applied to the Virtual Reconstruction of the Damaged Sculpture of St. John Nepomuk in Petrovaradin, Shape and Form Studies, Vol.(2), pp.388398.

${ }^{29}$ Horvath, A. (2011). The Complete Virtual 3D Reconstruction of the East Pediment of the Temple of Zeus at Olympia, International Archives of the Photogrammetry, Vol.38(5), pp.53-61.

${ }^{30}$ https://123dok.com/document/ye9pk8rq-isprsarchives-xxxviii-w.html

31 Horvath, A. (2011). The Complete Virtual 3D Reconstruction of the East Pediment of the Temple of Zeus at Olympia

${ }^{32}$ Gherardini, F., Santachiara, M. and Leali, F. (2018). 3D Virtual Reconstruction and Augmented Reality Visualization of Damaged Stone Sculptures, IOP CONFERENCE: Materials Science and Engineering, (364).

${ }^{33}$ Theodorus, A. (2019). Restoration of Damaged Face Statues Using Deep Generative Inpainting Model, Master Thesis, University of Twente, pp.66-78.

34 Siotto, E., Dellepiane, M., Callieri, M. and Scopigno, R. (2015). Ancient Polychromy: Study and Virtual Reconstruction Using Open Source Tools. Journal on Computing \& Cultural Heritage, Vol.8 (3).

35 Fu, T., Chaine, R. and Digne, J. (2020). Anatomy Changes and Virtual Restoration of Statues, EuroGraphics Workshop on Graphics and Cultural Heritage, Nov.2020, Grenade, Spain.

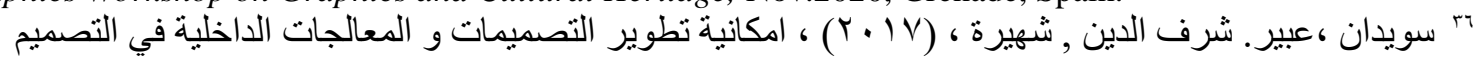

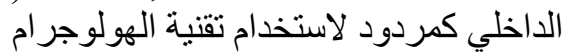

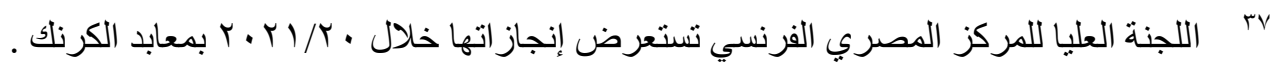

https://www.almasryalyoum.com/news/details/2276654 